\title{
¿Hay una antropología en el Documento de Puebla? Mediaciones filosóficas subyacentes
}

\author{
CAPÍTULO II \\ CARACTERÍSTICAS RESALTANTES DE LA VISIÓN \\ DEL DOCUMENTO DE PUEBLA SOBRE EL HOMBRE
}

El hecho de comenzar por la visión de Puebla sobre el hombre tiene la doble finalidad de presentar los criterios de Puebla sobre el hombre desde la perspectiva latinoamericana $\mathrm{y}$, al mismo tiempo, rastrear las palabras claves que, después, nos ayudarán para una hermenéutica adecuada de las filosofíassubyacentes ${ }^{1}$.

1. A. Salazar Bondy, Didáctica de la filosofía, Edit. Arica, Lima 1967, pp. 127-183; C. CASTILla del Pino, Introducción a la hermenéutica del lenguaje, Barcelona ${ }^{2} 1974$, pp. 77-146; J. SCHREINER, Introducción a los métodos de la exégesis bíblica, Herder, Barcelona 1974, pp. 61108; F. MARCos MARín, Lingüística y lengua española, Introducción, historia y métodos, Edit. Cincel, Madrid 1975, pp. 185-274; K. RAHnER, W. Thusing, Cristología. Estudio Teologico y Exegético, Cristiandad, Madrid 1975, pp. 83-300; SANS, DE GoITIA, AMENGUAL, Exégesis y teología, Edic. Deusto, Bilbao 1975, pp. 40-49; 268-273; D. ANTISIERI, El problema del lenguaje religioso, Edit Cristiandad, Madrid 1976, pp. 31-145; R. ANTONCICH, Hacia una mejör lectura de los documentos sociales del magisterio, Pontificia Universidad Católica del Perú, pp. 146 (mimeografiado); R. BARTHES... P. RICOEUR y otros, Exégesis y hermenéutica, Cristiandad, Madrid 1976, pp. 33-235;: A. GRABNER-HAIDER, Semiótica y teología. El lenguaje religioso entre la filosofía analítica y hermenéutica, Edit. Verbo Divino, Estella (Navarra), 1976, pp. 11-257; J. MAC QUARRIE, Gog-talk, El análisis del lenguaje y la lógica de la teología, Edit. Sígueme, pp. 178-299; GADAMER, Verdad y método. Fundamentos filosóficos de una hermenéutica filosófica, Edit Sígueme, Salamanca 1977, pp. 225-585; E. BALLÓN, «Introducción al estudio semiótico de la literatura étnica en el Perú», en Rev. Amazonía Peruana, n. 3 (1978) 53-98. (Es un estudio serio con amplia bibliografía sobre teorías de la interpretación); C. HERNÁNDEZ Alonso, Pautas para análisis lingüístico, Valladolid 1978, pp. 7-110; J.L. ILLANES, Sobre el saber teológico, Rialp, Madrid 


\section{A) SER DEL HOMBRE Y SU REALIZACIÓN HISTÓRICA}

Son los dos pilares de la antropología de Puebla. Es interesante estudiar los elementos de los cuales están constituidos.

\section{Ser del hombre}

\section{a) Visión integral del hombre}

Le interesa a «Puebla» tener en cuenta la imagen del hombre concebida por la filosofía y los aportes de las demás ciencias humanas, pero no en general; especifica en qué sentido se refiere al hombre integral: se refiere al ser del hombre y a su realización histórica.

Puebla no se escapa por la tangente. Tiene en cuenta al hombre en sí, pero no se queda en un subjetivismo, ni en un historicismo. Tiene presente las adquisiciones de la filosofía perenne y los aspecto positivos de la filosofía moderna: el ser del hombre y su realización histórica ${ }^{2}$. Además, abre al hombre al sentido trascendente y religioso:

La fe en Cristo nos ofrece.así, los criterios fundamentales para obtener una visión integral del hombre que, a su vez, ilumina y completa la imagen concebida por la filosofía y los aportes de las ciencias humanas, respecto al ser del hombre y a su realización histórica ${ }^{3}$.

Se centra por tanto en el meollo del problema sobre el hombre y no se escapa por la tangente. Quiere una visión integral pero del ser del hombre y de su realización histórica ${ }^{4}$.

1978, pp. 69-279; M. PAGNINI, Estructura literaria y método crítico, Cátedra, Madrid ${ }^{2}$ 1978, pp. 125-167; J. SADABA, Filosofía, lógica, religión, Edic. Sígueme, Salamanca 1978, pp. 13-48; M. VeXLeR, «Naturaleza y dificultades de los textos filosóficos», en Rev. Aporía, Revista filosófica, Lima n. 4 (1978) 1-7; E. CARONTINI, D. PERAYA, Elementos de semiótica general. El proyecto semiotico, Edit. Gustavo Gili, Barcelona 1979, pp. 17-113; I.M. BocHENSKI, Los métodos actuales del pensamiento, Rialp, Madrid ${ }^{13}$ 1979, pp. 37-254; U. Eco, Lector in fabula. La cooperazione interpretativa nei testi narrativi, Edit. Bompiani, Milano 1979, pp. 13-49; GRUPO DE ENTREVERNES, Signos y parábolas. Semiótica y texto evangélico, Edic. Cristiandad, 1979, pp. 16-22; J.B. Metz, La fe en la historia y en la sociedad, Cristiandad, 1979.

Estos estudios nos servirán de apoyo para el análisis de interpretación de los textos. No añadimos aquí la bibliografía sobre las metodologías de las teologías subyacentes por no prolongar más esta lista de bibliografía y porque son conocidas de los que están familiarizados con las corrientes de teología. Es, quizá, suficiente de momento citar la obra de A. MARRANZINI y otros, Citta Nuova Editrice, 1974.

2. J. MARIAS, El tema del hombre, Espasa-Calpe, ${ }^{3}$ 1960, pp. 13-16.

3. Documento de Puebla, n. 305.

4. Mons. J. Lozano, Síntesis del documento, Colección Puebla, CELAM, Bogotá 1979, pp. 29-31. 
Y a partir de esta concepción sobre el hombre, juzga, rechaza y critica las teorías e ideologías que pululan actualmente en nuestro continente y que parcializan o deforman aspectos de una visión integral del hombre ${ }^{5}$.

Se alegra, en concreto, de que se legisle sobre los derechos humanos en nuestros pueblos ${ }^{6}$. Pero ${ }^{7}$, en número anterior, recalca, de nuevo el sentido en que se enmarcan los derechos humanos:

Por ser hombres necesitamos de la sociedad en que estamos inmersos y que vamos transformando y enriqueciendo con nuestro aporte en todos los niveles, desde la familia y los grupos intermedios, hasta el Estado cuya función indispensable ha de ejercerse al servicio de las personas y la misma comunidad internacional. Su integración es necesaria, sobre toda la integración latinoamericana ${ }^{8}$.

La visión integral del hombre va a suponer un ser humano, compuesto de alma y cuerpo, hecho a imagen y semejanza de Dios y que se realiza en la comunidad y en la historia. Quiere huir Puebla de una reducción a un verticalismo desencarnado que busca simplemente la unión espiritual con Dios, así como tampoco quiere caer en un simple personalismo existencial de lazos entre individuos o pequeños grupos $\mathrm{y}$, mucho menos, en un horizontalismo socioeconómico-político ${ }^{9}$.

Hace hincapié en tres planos para resaltar este sentido integral del hombre: la relación del hombre en el mundo, como señor; con las personas como hermanos y con Dios como hijos ${ }^{10}$. A cada momento, sin embargo, vuelve a insistir en que la plenitud del hombre se encuentra en Cristo, teniendo, al mismo tiempo en cuenta, la totalidad de planos en que se desenvuelve el hombre:

Nos liberamos por la participación en la vida nueva que nos trae Jesucristo y por la comunión con él, en el misterio de su muerte y su resurrección, a condición de que vivamos ese misterio en los tres planos ya expuestos, sin hacer exclusión de ninguno de ellos ${ }^{11}$.

Nos vamos encontrando con varias palabras claves para clarificar la con-

5. Puebla, n. 307.

6. Id., n. 337.

7. Id., n. 336 .

8. Id., n. 336.

9. Id., nn. 336, 329, 1026

10. Id., n. 322.

11. Id., n. 329. 
cepción del hombre en Puebla, y, que al mismo tiempo, nos servirá para intentar esclarecer la mediación filosófica de la que proviene ${ }^{12}$.

Tenemos las siguientes palabras: visión integral del hombre, en comunidad, en la historia, imagen de Dios, persona, opción personal, dignidad de la persona, libertad y liberación, comunión y participación, hombre nuevo en Jesucristo.

\section{b) Sentido de la vida}

Una de las razones fundamentales por las que quiere Puebla insistir sobre el hombre, es para que, esos cerca de trescientos millones de hombres que viven en latinoamérica, en condiciones poco dignas, tanto desde el punto de vista económico, social, político como desde el punto de vista religioso - en situación de pecado personal y estructural, o mejor en pecado solidario con más o menos responsabilidad personal- descubran el sentido pleno de la vida, desde el aspecto humano y desde la iluminación cristiana.

El ser más y no el tener más es uno de los aspectos fundamentales que el hombre de hoy ha descubierto y redescubierto y por el cual, en las capas más concientizadas, se da la vida ${ }^{13}$. El mensaje cristiano quiere resaltar este aspecto humano y plenificarlo por la encarnación de Jesucristo, como modelo vivencial histórico, con el cual se plasma el destino de Dios sobre el hombre y la plenitud de las aspiraciones del hombre en Dios. Además, de ahí se sacará la fuerza para luchar por la realización histórica y escatológica del hombre, con la Gracia de Jesucristo:

El pecado está minando la dignidad humana que Cristo ha rescatado. A través de su mensaje, de su muerte y resurrección, nos ha dado su vida divina: dimensión insospechada y eterna de nuestra existencia terrena. Jesucristo, viviente en su Iglesia, sobre todo los más pobres, quiere hoy enaltecer esta semejanza de Dios en su pueblo: por la participación del Espíritu Santo en Cristo, también nosotros podemos llamar Padre a Dios y nos hacemos radicalmente heruanos. Él nos hace tomar conciencia del pecado contra la dignidad humana que abunda en América Latina; en cuanto este pecado destruye la vida divina en el hombre, es el mayor daño que una persona puede inferirse a sí misma y a los demás. Jesucristo, en fin, nos ofrece su gracia más abundante que nuestro pecado. De Él nos viene el vigor para liberarnos y liberar a otros del misterio de iniquidad ${ }^{14}$.

\footnotetext{
$31-72$.

12. E. CoReth, Cuestiones fundamentales de hermenéutica, Herder, Barcelona 1973, pp.

13. Id., n. 339.

14. Id., n. 330, 306, 338, 339, 1206.
} 
Las palabras claves que pudiéramos considerar en este apartado son: el sentido pleno de la vida y el ser más.

\section{c) El hombre se concretiza en la persona humana}

El ser humano que se realiza en la-historia no es un ente abstracto; está concretizado en la persona. La imagen de Dios que es el fundamento cristiano de la dignidad de la persona humana está en la persona. La solidaridad en el pecado le afecta a la persona. La libertad es de la persona. Por eso nos dice Puebla que:

...la Iglesia tiene el derecho y el deber de anunciar a todos los pueblos la visión cristiana de la persona humana, pues sabe que la necesita para iluminar la propia identidad y el sentido de la vida y porque profesa que todo atropello a la dignidad del hombre es atropello al mismo Dios, de quien es imagen ${ }^{15}$.

Aquí tenemos como clave el concepto de persona.

\section{d) Opción total}

Decíamos que Puebla no se queda en lo periférico del hombre puesto que va al ser del hombre y su manifestación histórica. Quiere abarcar todas las dimensiones del hombre, no para lograr una filosofía propia, sino para utilizar las mediaciones fílosóficas más adecuadas y poder transmitir la plenitud del mensaje evangélico que plenificará al hombre. Uno de los aspectos importantes es la referencia al sentido moral del hombre. Exige una opción total por Cristo. La moral, el fundamènto de la moral, se va a manifestar a través de la opción fundamental que se manifestará en aptitudes y se concretizará en actos ${ }^{16}$.

Evidentemente está utilizando los conceptos existencial-personalistas de opción, actitud y actos usados por la Moral actual y aquí no aparecen los conceptos escolásticos de potencia, hábito y acto. Se recalca más en la opción y la actitud que en el acto. Se va de la opción al acto por contraposición clara a los abusos de la moral casuística nominalista, pues ésta se preocupaba mucho más del acto que de la responsabilidad de la persona, tanto a nivel individual como a nivel solidario o estructural.

No es que Puebla deje de lado el acto, pero utiliza palabras muy significativas: eficaz y radical conversión ${ }^{17}$. Conversión no solamente en sentido individual:

15. Id., nn. 306, 1034, 318, 336.

16. En la parte del actuar constantemente se está utilizando esta terminología. La palabra opción es continuamente repetida en el documento de Puebla. Y cuando se va a definir la fe, se hace con esta terminología. Cfr. Puebla n. 1300.

17. Id., n. 1206, 1302-1305, 999. 
...una radical conversión a la justicia y al amor, a transformar desde dentro las estructuras de la sociedad pluralista que resputen y promuevan la dignidad de la persona humana y le abran la posibilidad de alcanzar su vocación suprema de comunión con Dios y de los hombres entre sí ${ }^{18}$.

Se habla de conducta personal y social. de plena madurez, más que simples actos ${ }^{19}$.

O sea, el fundamento moral del hombre arranca de la opción, se manifiesta en actitudes y se concretiza en actos eficaces ${ }^{20}$.

\section{e) Dignidad de la persona}

La Iglesia latinoamericana, representada en Puebla, se siente con la obligación de proclamar en alta $\mathrm{v}, \mathrm{z}$ la dignidad que corresponde a todos los hombres y que, sin embargo, vemos a cada paso pisoteada ${ }^{21}$. Esa dignidad exige confesar ante el mundo:

...que todo hombre y toda mujer por más insignificantes que parezcan, tienen en sí una nobleza inviolable que ellos mismos y los demás deben respetar y hacer respetar sin condiciones; que toda vida humana merece por sí misma, en cualquier circunstancia su dignificación; que toda convivencia humana debe fundarse en el bien común, consistente en la realización cada vez más fraterna de la común dignidad, lo cual exige no.instrumentalizar a unos en favor de otros y estar dispuestos a sacrificar aún bienes particulares ${ }^{22}$.

Como consecuencia del respeto a la dignidad, condena, Puebla:

...todo menosprecio, reducción o atropello de las personas y sus derechos inalienables; todo atentado contra la vida humana, desde la oculta en el seno materno, hasta la que se juzga como inútil y la que se está agotando en la ancianidad; toda violación o degradación de la convivencia entre los individuos, los grupos sociales y las naciones ${ }^{23}$.

La motivación cristiana mueve a los responsables de su cristianismo a unirse a todos los hombres de buena voluntad que luchan por resaltar la dignidad de la persona humana:

Sola la aceptación y el seguimiento de Cristo nos abre a las certidumbres más confortantes y a las exigencias más apremiantes de la dignidad humana, ya

18. Id., nn. $1206,358,193,1183,998,973,1134,1140,1157$.

19. Id., n. 1300 .

20. Id., n. 320 .

21. Id., n. 316 .

22. Id., n. 317 .

23. Id., n. 318. 
que ésta radica en la gratuita vocación a la vida que el Padre Celestial va haciendo ir de modo nuevo, a través de los combates y de las esperanzas de la historia. Pero no nos cabe duda de que, al luchar por la dignidad, estamos unidos también a otros hombres lúcidos que, con un esfuerzo sincero por liberarse de engaños y apasionamientos, siguen la luz del espíritu que el Creador les ha dado, para reconocer en la propia persona y en la de los demás un don magnífico, un valor irrenunciable, una tarea trascendente ${ }^{24}$.

La dignidad de la persona es por tanto, consecuencia de los presupuestos humanos y cristianos sobre el hombre.

\section{f) La libertad}

La dignidad se enraíza en la persona y no se puede entender a la una ni a la otra sin libertad.

La libertad es una característica fundante del ser del hombre que se plenifica con el nivel cristiano. Hoy la libertad se manifiesta violentamente, inclusive, como signo de los tiempos. Tanto los hombres como las sociedades pugnan por ser libres y por liberarse:

La libertad implica siempre aquella capacidad que en principio tenemos todos para disponer de nosotros mismos a fin de ir construyendo una comunión y una participación que han de plasmarse en realidades definitivas sobre tres planos inseparables ${ }^{25}$.

Puebla quiere aclarar esos planos de la liberación: «...la relación del hombre con el mundo, como Señor; con las personas como hermanos y con Dios como hijo» ${ }^{26}$.

Aquí hay algo característico: la libertad se amplía a la liberación y se especifica el alcance de esta liberación. Puebla en los números 323-329 hace una detallada explicación sobre cada uno de los tres planos mencionados y concluye con una acertada síntesis de conjunto ${ }^{27}$. Integra el plano humano y el cristiano.

Las palabras claves aquí son libertad y liberación.

24. Id., n. 319.

25. Id., n. 322 .

26. Id., n. 322 .

27. Id., nn. 323-329, 321, 322, 330-335. 
g) El hombre imagen de Dios

El fundamento del ser del hombre cristiano está en que es imagen de Dios. Puebla recoge los textos bíblicos y toda la tradición cristiana:

Jesucristo ha restaurado la dignidad original que los hombres habían recibido al ser creador por Dios a su imagen, llamados a una santidad o consagración total al Creador y destinados a conducir la historia hacia la manifestación definitiva de ese Dios, que difunde su bondad para alegría eterna de sus hijos en un reino que ya ha comenzado ${ }^{28}$.

\section{h) El Hombre nuevo en Jesucristo}

La dimensión total y, que plenifica la dimensión trascendente, está en Cristo. Él es el principio y el fin, pero, al mismo tiempo, es el modelo donde se encuentran todas las dimensiones de la plenitud del hombre. Por eso se nos invita a seguir al hombre renovado en Cristo, al hombre nuevo en Cristo, que abarca, al hombre total, tanto en su ser como su actuar en la historia. El ser cristiano, se encuentra en grado sumo, porque es la verdadera imagen de Dios $\mathrm{y}$, en su actuar, porque es el mediador salvífico; el auténtico liberador que con su libertad plenifica al hombre haciéndole hijo de Dios y, su actuar en la historia, la convierte en Historia de Salvación, puesto que ha iniciado el Nuevo Reino de Dios, donde los hombres se amarán como hermanos por ser de la familia de los hijos de Dios y la sociedad buscará el reino de justicia, de amor y de paz:

Jesucristo ha restaurado la dignidad original que los hombres habían recibido al ser creados por Dios a su imagen, llamados a una santidad o consagración total al Creador y destinados a conducir la historia hacia la manifestación definitiva de ese Dios, que difunde su bondad para alegría eterna de sus hijos en un Reino que ya ha comenzado ${ }^{29}$.

Aquí, aparece una connotación que hay que resaltar: la concepción dinámica de Cristo, de Dios, del Reino y la participación activa de los hombres en la construcción de ese Reino como respuesta a la invitación de Dios a través de Cristo.

Y esta respuesta que exige Cristo la recalca Puebla claramente para el hombre latinoamericano:

28. Id., n. $331,306,333$.

29. Id., n. $330,329,330-339$. 
Es necesario crear en el hombre latinoamericano una sana conciencia moral, sentido evangélico crítico frente a la realidad, espíritu comunitario y compromiso social. Todo ello hará posible una participación libre y responsable, en comunión fraterna y dialogante para la construcción de la sociedad verdaderamente humana y penetrada de valores evangélicos. Ella ha de ser modelada en la comunión del Padre, del Hijo y del Espíritu Santo y debe ser respuesta a los sufrimientosey aspiraciones de nuestros pueblos, llenos de esperanza que no podrá ser defraudada ${ }^{30}$.

Se aprecia una concepción dinámica, histórica, temporal, social activada por la dimensión escatológica de Cristo.

\section{Realización histórica del hombre}

Cuando Puebla nos habla del hombre integral, acentúa dos aspectos que recoge de la filosofía y de las ciencias humanas: «...lo que respecta al ser del hombre y a su realización histórica» ${ }^{31}$.

El primer punto intentamos presentarlo. El segundo, el de la realización histórica del ser del hombre, es muy importante. Puebla lo coloca a la misma altura del ser del hombre, o sea, está en el centro del hombre. Este segundo punto es el que estudiaremos ahora.

Podemos distinguir los dos aspectos que hace el mismo documento de Puebla: aspecto humano y aspecto cristiano.

\section{a) Aspecto humano}

El hombre es señor del mundo y debe humanizarlo a través del trabajo y de la sabiduría proyectada - en comunidad de esfuerzos múltiples sobre el mundo material de la naturaleza y la técnica ${ }^{32}$.

$\mathrm{Al}$ mismo tiempo, tiene que humanizar y fraternizar las relaciones humanas:

...Dios nos da la existencia en un cuerpo por el que podemos comunicarnos con los demás y ennoblecer el mundo; por ser hombre necesitamos de la sociedad en que estamos inmersos y que vamos transformando y enriqueciendo, con nuestro aporte en todos los niveles, desde la familia y grupos intermedios, hasta el Estado cuya función indispensable ha de ejercerse al servicio

30. Id., n. 1308.

31. Id., n. 305.

32. Id., nn. $323,477$. 
de las personas y la misma comunidad internacional. Su integración es necesaria sobre todo la integración latinoamericana ${ }^{33}$.

El hombre debe llegar al cambio de estructuras si es necesario:

El evangelio nos debe enseñar que, ante las realidades que vivimos, no se puede hoy en América Latina amar de veras al hermano y por lo tanto a Dios, sin comprometerse a nivel personal y, en muchos casos, inclusive, a nivel de estructuras, con el servicio a la promoción de los grupos humanos y de los estratos sociales más desposeídos y humillados, con todas las consecuencias que se siguen en el plano de esas realidades temporales ${ }^{34}$.

Además, es agente de su historia, pues cada hombre y cada pueblo tiene derecho a hacer su propia historia:

En esta pluralidad e igualdad de todos, cada uno conserva su valor y su puesto irrepetibles, pues también cada hombre latinoamericano debe sentirse amado por Dios y elegido por Él eternamente, por más que lo envilezcan, o por poco que se estime a sí mismo. Personas en diálogo, no podemos realizar nuestra dignidad sino como dueños o responsables del destino común, para el que Dios nos ha capacitado; inteligentes, es decir, aptos para discernir la verdad y seguirla frente al error y al engaño; libres, no sometidos inexorablemente a los procesos ecọnómicos y políticos, aunque humildemente nos reconozcamos condicionados por éstos y obligados a humanizarlos; sometidos, en cambio, a una ley moral que viene de Dios y se hace oír en la conciencia de los individuos y de los pueblos, para enseñar, para amonestar y reprender, para llenarnos de la verdadera libertad de los hijos de Dios ${ }^{35}$.

\section{b) Aspecto cristiano}

Al hombre le toca en la historia construir el Reino de Dios ${ }^{36}$.

Como cristianos, además tenemos que luchar por liberar al hombre del pecado solidario y de su responsabilidad, tanto en el pecado personal como en el estructural para que se realice la construcción del Reino ${ }^{37}$.

Esta construcción del Reino de Dios exige un compromiso, un empeño para lograr que la historia humana sea historia de salvación ${ }^{38}$.

33. Id., n. 336 .

34. Id., nn. $327,318$.

35. Id., n. 335 .

36. Id., nn. $331,335,1206-1293$.

37. Id., nn. 328, 335.

38. Id., nn. 338, 339, 320, 279, 319, 331, 335. 
Jesucristo aparece como el principio y el fin de la historia de la Salvación; es el mediador salvífico y el activador de esta historia ${ }^{39}$.

Al cristiano le toca, además, realizar la liberación plena en Cristo. La palabra liberación, la utiliza Puebla como término clave para expresar el mensaje cristiano por el hombre. Pero, la usa adjetivandola para evitar ambigüedades puesto que esta palabra es manejada en diversos sentidos, ya sea en las corrientes filosóficas o en las teológicas. Por eso, habla de liberación integral, liberación plena ${ }^{40}$. Su intención es la de matizar el sentido positivo, con que se ha enriquecido el concepto de liberación, bajo el criterio bíblico con la finalidad de buscar la plenitud de lo humano, sin excluir ninguna dimensión ${ }^{41}$.

El hombre como ser en la historia, o más bien, la realización histórica del hombre, su liberación aparecen en Puebla como conceptos claves que abarcañ un conjunto de palabras significativas que acabamos de ver brevemente. Sin embargo, sobresale la idea de liberación que marca la antropología de Puebla como una antropología liberadora debidamente matizada.

La liberación quiere ser integral, total. Va desde el pecado individual al social; de todo tipo de esclavitudes económicas, sociales, políticas, estructurales hasta una apertura a lo trascendente y a la realización del Reino de Dios; una liberación desideologizada y bíblica.

Esta liberación viene acompañada por lo que se ha constituido en el lema de Puebla: comunión y participación, co-participación. Una comunión y participación que expande la liberación en tres planos fundamentales inseparables: la relación del hombre con el mundo como señor; la relación interpersonal en fraternidad y, por fin, la relación trascendente con Dios como hijo.

\section{Palabras claves}

La síntesis de la antropología de Puebla se centra en las dos palabras claves: ser del hombre y su realización histórica.

El ser del hombre és dinámico, existencial, personalizante. Además de ser digno de respeto por ser hombre, adquiere su máxima dignidad porque su constitución radica en ser imagen de Dios. Este ser humano, imagen de Dios es libre, se relaciona con los demás hombres como hermanos y está abierto a todas las dimensiones del hombre, inclusive, a la trascendente. El hombre en la antropología de Puebla se concibe desde la visión cristiana. Su fundamento

39. Id., nn. 330, 331, 188, 189.

40. Id., nn. $479,485,490,141,475,895,1134,452,979,1026,481,488$.

41. «La liberación es, pues, una llamada a no buscar como meta la realización del homo religiosus, sino a buscar la plenitud de lo humano en toda su misteriosa amplitud. Puebla expresa así el enfoque liberador: «Es un anuncio que urge a la Iglesia y que pertenece a la entraña misma de una evangelización que tiende hacia la realización auténtica del hombre» (n. 480). Es, por tanto, «liberación de lo que oprime al hombre, pero sobre todo liberación del pecado y del maligno» (n. 354). Por tanto «abarca las diferentes dimensiones de la existencia: lo social, lo político, lo económico, lo cultural y el conjunto de sus relaciones» (n. 483). Y dentro de esas dimensiones 
último está en Dios y es analizado en su mismidad y en su circunstancia histórica a la luz de Cristo. Él es la luz hermenéutica, gnoseológica; Él es el modelo orientador del hombre en todos sus planos y posibilidades. La moral del hombre también se ajusta a esta orientación.

La otra palabra clave es la realización histórica del hombre. No se queda el hombre cristiano en sí mismo, ni en una pura trascendencia, o en una escatología. Quiere conjugar lo subjetivo y lo real, la inmanencia y la trascendencia. El hombre se relaciona con los demás como hermanos y es señor de la historia. Por eso busca la liberación de toda esclavitud, inclusive, no solamente buscando la realización personal, sino, si es necesario, también la transformación de las estructuras injustas que impiden la realización histórica del hombre, pues debe ir en el camino de la construcción del Reino de Dios, ya en este mundo.

Aquí utiliza Puebla la palabra liberación, de un contenido rico y complejo, aunque puede dar lugar a ambigüedades e ideologizaciones -especialmente la marxista - de las cuales ha querido huir Puebla, introduciéndola en un co' texto bíblico y cristiano. Por eso, podemos calificar a la antropología de Puebla como antropología cristiana de liberación integral o total.

El ser del hombre y su realización histórica se despliega en un abanico de palabras clave que parten del mismo centro del hombre para explicar sus distintos aspectos fundamentales - después, estas palabras nos valdrán para detectar las filosofías subyacentes-:

Ser humano.

Ser integral.

Sentido de la vida, vocación trascendencia.

Alma encarnada, no cuerpo animado.

Ser sobre tener más.

El hombre se concretiza en la persona.

Opción total.

Dignidad de la persona.

Libertad.

El hombre imagen de Dios.

Hombre nuevo en Cristo.

Realización histórica.

Liberación.

Realizāación en fraternidad.

Co-participación, o sea, comunión y participación.

abarca «la dimensión terrena y trascendente», la que se realiza en la tierra y la que culmina en el más allá, «contribuyendo así a la construcción del Reino último y definitivo» (n. 475). Cfr. J.L. Idigoras, «La liberación en Puebla», en Rev. Teol. Limense, vol. XIII, n. 3 (1979) 319; PuEBLA nn. 321-329, 472-503, 1027-1038, 1026, 331, 335. 
B) ¿HAY UNA ANTROPOLOGÍA EN PUEBLA? ¿QUÉ TIPO?

Importa plantearnos, de una vez, si hay antropología en Puebla y qué tipo de antropología. Para ello, será conveniente auscultar opiniones, ver qué tipo de antropología nos proponen, analizar los elementos antropológicos de Puebla y sacar a la luz las conclusiones a que nos haya llevado todo esto.

\section{Opiniones}

Hay opiniones en que tajantemente se afirma la existencia de una antropología e, inclusive, que nosotros tenemos la verdad sobre el hombre; una visión propia que ha querido clarificar Puebla para que el cristiano latinoamericano sepa tener criterios adecuados y rechazar las otras visiones sobre el hombre que están dañando, de una forma u otra, el ser del hombre y su realización histórica. Por eso, en definitiva, llaman a la antropología de Puebla, antropología cristiana. Y la razón es que se apoya en los elementos revelados sobre la naturaleza del hombre y sus dimensiones. Sin embargo, no olvida que, hay que tener también en cuenta, el progreşo de la reflexión sobre el hombre porque, cuando es positiva, complementa al pensamiento cristiano y se origina un enriquecimiento mutuo ${ }^{42}$. Precisamente, le interesa desentrañar a la luz de la revelación, el sentido de la reflexión humana sobre el hombre ${ }^{43}$.

Pablo VI pone de manifiesto que la Iglesia no va a dar técnicas ni programas sino lo que es propio de ella: su visión sobre el hombre ${ }^{44}$.

Juan Pablo II les dice en Puebla a los obispos que no son técnicos, sino maestros de la verdad. $Y$, que en estas circunstancias, les toca decir la verdad

42. Insiste en la necesidad del diálogo con las antropologías modernas porque para «conocer a Dios, es menesier conocer al hombre». Cfr. PABLO VI, Discurso de clausura de la IV sesión del Concilio Vaticano II.

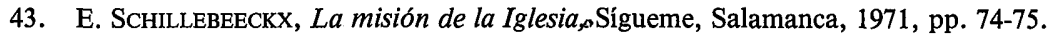

44. «Tomando parte en las mejores aspiraciones de los hombres y sufriendo al no verlas satisfechas, desea ayudarles a conseguir su pleno desarrollo y esto precisamente porque ella les propone lo que ella posee, como propio: una visión global del hombre y de la humanidad». Cfr. PABLO VI, «Populorum Progressio», n. 13; Moyano comenta este texto con las siguientes palabras: «pero, fiel a su misión inculca a los hombres el amor a la verdad y las exigencias de la justicia, las responsabilidades de la solidaridad, y la vigencia de los valores humanos permanentes.

Alienta toda iniciativa noble y generosa y participa de las aspiraciones de los hombres...

A la luz del Evangelio interpreta los sucesos de los tiempos presentes y convoca a los hombres para la acción solidaria...

No esperemos, pues, descripciones analíticas o estadísticas... Tampoco programas técnicos de acción. Las descripciones de situaciones son simplemente «humanas». Las enseñanzas para la acción son doctrinales.

...Cambiadas las mentalidades asumidas y las responsabilidades personales, las soluciones y programas técnicos para el desarrollo humano no tardarán en surgir». Cfr. A. Moyano CouDERT, Esta hora del desarrollo, Edit. Guadalupe, Buenos Aires 1967, p. 68. 
sobre tres pilares fundamentales acerca de los que hay confusión. Se refiere al trípode: Cristo, Iglesia, hombre. No se trata de una «verdad humana y racional, sino de la Verdad que viene de Dios» ${ }^{45}$. En este sentido se podría dar el apelativo de antropología cristiana a la visión que se origina con relación al hombre, pues trata de clarificar a la luz de la fe, la verdad sobre el hombre. Ya tenemos la verdad que viene de Dios, pero las circunstancias hacen qüe la reflexión actual sobre el hombre que existe en latinoamérica, sea contrastada con la revelación para aclarar los principios fundamentales sobre el hombre ${ }^{46}$. Sin embargo, el método que propone Juan Pablo II es deductivo porque se parte de la Verdad que viene de Dios y se insiste, no solamente en la unión en la caridad, sino en la verdad. La verdad nos hace libres, da paz al corazón y nos acerca a Dios ${ }^{47}$. A la luz de esta verdad, el hombre no está sometido a los vaivenes de los proyectos económicos o políticos sino, por el contrario, estos proyectos deben estar al servicio del hombre y controlados por él.

La verdad sobre el hombre comienza por la verdad sobre él mismo. Y esto tiene un significado especial hoy que a pesar de tantas corrientes antropológicas existentes que se arrogan la posesión de la verdad sobre el hombre, vemos, quizá como nunca, «las más hondas angustias del hombre respecto de su identidad y destino, del rebajamiento del hombre a niveles antes insospechados, época de valores humanos conculcados como jamás lo fueron antes» ${ }^{48}$. La verdad que la Iglesia tiene sobre el hombre está por encima de todo sistema filosófico o político, porque quien se la ha enseñado es Jesucristo. La Iglesia es, simplemente, testigo y portavoz de esa verdad ${ }^{49}$. Quizá esto no lo entienda mucha gente, porque hoy se percibe la amputación de una dimensión esencial del ser del hombre cual es lo trascendente, lo religioso, propiciado, especialmente, por un humanismo ateo positivista.

Insiste el papa, en que la Iglesia tiene una antropología «que no cesa de comunicar y profundizar» ${ }^{50}$. Pero, la entenderán los que están abiertos a lo absoluto, a Dios, ya que el principio fundamental de esta antropología, está en el ser el hombre imagen de Dios. Con ello supera todo reduccionismo a cualquier «parcela de la naturaleza humana o a un elemento anónimo de la ciudadanía humana» ${ }^{51}$. Así, resulta el hombre «uno, único e irrepetible... al-

45. Juan Pablo II, Discurso inaugural de Puebla, I.; A. LoRscheider, El documento de Puebla. Un intento de síntesis, en Puebla. Grandes Temas. I. Parte, CELAM, Bogotá, pp. I-II.

46. JUAN PABLo II, O.c., III. 7.

47. Id., ib., 1.1.

48. Id., O.c., 1.9 .

49. Id., ib.

50. Id., ib.

51. Id., ib. 
guien eternamente ideado y eternamente elegido: alguien llamado y denominado por su nombre» ${ }^{52}$.

$\mathrm{Al}$ esclarecer la verdad sobre el hombre, se hace un servicio a la integridad del ser del hombre y lo defiende, en su dignidad, contra los diversos tipos de humanismo que lo encierran en una visión estrictamente económica, biológica o psíquica. Del evangelio ha aprendido, también, y proclama en su antropología - aunque la misión de la Iglesia no es social o política propiamente-, la indispensable acción por la justicia, la promoción humana, la defensa de los derechos de la persona ${ }^{53}$. Esto pone a la antropología cristiana en relación con el concepto de liberación ${ }^{54}$. Sin embargo, aquí tampoco tiene que recurrir a sistemas o ideologías para definir este concepto, puesto que el mensaje evangélico, da elementos suficientes para definirlo y clarificarlo:

...; y al hombre tal como ella lo ve en la visión cristiana de la antropología que adopta. Ella no necesita pues recurrir a sistemas o ideologías para amar, defender y colaborar en la liberación del hombre: en el centro del mensaje del cual es depositaria y pregonera, ella encuentra inspiración para actuar en favor de la fraternidad, de la justicia, de la paz, contra todas las dominaciones, esclavitudes, discriminaciones, violencias, atentados a la libertad religiosa, agresiones contra el hombre y cuanto atenta a la vida ${ }^{55}$.

Aparece demostrado, con esto, que, por el hecho de ser una antropología de carácter religioso, no se despreocupa de lo social, de lo político, de lo histórico ya que la integridad del ser incluye estas dimensiones:

Fiel a este compromiso, la Iglesia quiere mantenerse libre frente a los opuestos sistemas, para optar sólo por el hombre. Cualesquiera sean lạs miserias o sufrimientos que aflijan al hombre; no a través de la violencia, de los juegos de poder, de los sistemas políticos, sino por medio de la verdad sobre el hombre, camino hacia un futuro mejor ${ }^{56}$.

Tiene que quedar patente, no obstante, que la antropología cristiana se enriquece, es dinámica, está abierta «a la interpelación recíproca que en el curso de los tiempos se establece entre el evangelio y la vida concreta, personal y social del hombre» ${ }^{57}$. Pero, el Papa que es filósofo, apoya la antropólogía cristiana sobre la verdad acerca del hombre y de ahí saca las consecuencias ${ }^{58}$.

52. Id., ib.

53. Id., O.c., III, 2.

54. Id., O.c., I, 9; III, 2 ; III, 6.

55. Id., O.c., III, 2.

56. Id., O.c., III, 3.

57. Id., O.c., III, 2.

58. J. Hoyos VÁsQueZ, «La ịmagen del hombre en Pụebla», en Rev. Theológica Xaveriana 51 (1979) 141. 
Hoyos Vásquez, rechaza, por su parte, las calificaciones de una simple antropología filosófica a la de Puebla y, más bien, la explica como una antropología cristiana apoyándose en el texto de Puebla: «...no es una verdad que poseamós como algo propio. Ella viene de Dios. Ante su resplandor experimentamos nuestra pobreza» ${ }^{59}$. Sin embargo, rechaza toda antropología dualista o desencarnada y propicia una antropología cristiana que se enriquece en la continua interpelación con las diversas concepciones sobre el hombre.

Para Alfonso López Trujillo, personaje protagónico de Puebla, sea por su cargo de Secretario General del CELAM, sea por sindicársele como líder de una corriente de pensamiento, afirma sin ambages que hay una antropología cristiana en Puebla ${ }^{60}$. Parte de un principio: «Puebla ha sido una paciente búsqueda de lo original católico. Su respuesta es síntesis muy válida. No evade los grandes problemas. Los ventila con fuerza, buscando lo que a la Iglesia y al católico le corresponde» ${ }^{61}$. Es fácil entender, desde este punto de vista que plantea, el calificativo que da a la antropología de Puebla: es una antropología cristiana ${ }^{62}$.

David Kapkin, no duda en denominar antropología cristiana, a la de Puebla, especificando que, evidentemente, se encuentran en el documento simplemente las líneas directrices ${ }^{63}$.

59. Puebla, n. 165: «Para el cristianismo toda ła historia está dirigida hacia el hombre y por el hombre, para que en ella y por medio de ella el hombre entre libremente a compartir la vida misma del Creador, Uno y Trino a la vez. Por medio de Cristo, que es Dios y hombre a la vez, se le revela al hombre lo que hay en él: su dignidad más grande. En Cristo, el mismo Dios quiso hacer una antropología, esto es, entrar en diálogo con el hombre, de igual a igual, ya que Cristo es un hombre perfecto. Y lo hizo para revelar al hombre lo que hay en él: qué es propiamente serhombre. Con esto nos indica la revelación que la palabra que Dios nos tiene que decir sobre el hombre no le es extraña, alienante, sino que nace desde su propia entraña de hombre, como algo a lo que ya estaba a la espectativa; una necesidad sentida, tanto más cuanto imposible de ser satisfecha por los propios recursos». Cfr. J. HoYos VÁSQUEZ, O.c., p. 140.

60. Actualmente es Presidente del CELAM, como es conocido" de todos.

61. A. López Trujillo, Perfiles de Puebla, Colección Puebla, CElaM, n. 3, Bogotá 1979 , p. 32.

62. «En esta antropología cristiana, que implica a la vez la Cristología, se apoya todo el discurso sobre la dignidad humana y la defensa de los derechos fundamentales...

La antropología de Puebla se inscribe en ese ir hacia el hombre, que no constituye un desvío sino una orientación normal de la Iglesia. «ella no se ha desviado sino que ha vuelto hacia el hombre.... La religión católica y la vida humana reafirman así su alianza... para conocer al hombre, al hombre verdadero es necesario conocer a Dios». Eran estas palabras de Pablo VI en su célebre Discurso del 7 de diciembre de 1965.

...Es una antropología que hunde sus raíces en el misterio mismo de la Encarnación». Cfr. Id., O.c., pp. 47-48; Id., Meditación sobre Puebla, en PuEBLA. Grandes temas. 38/CELAM, Bogotá, p. 7.

63. D. KAPKIN, Reflexiones sobre el marco doctrinal del documento de Puebla, Col. Puebla, 9.1, CELAM, Bogotá 1979, p. 19. 
Jorge Jiménez Carvajal tampoco tiene reparos en designar como antropología cristiana a la profundización de Puebla sobre el hombre. El poner esta antropología en Puebla, el aclarar la verdad sobre el hombre ha valido para sensibilizar sobre la realidad actual del hombre latinoamericano y sobre la necesidad de luchar por poner todos los medios necesarios para que se realice dignamente la persona humana en "esta historia. La particularidad de esta visión antropológica es que quiere ser total y por encima de cualquier reduccionismo. Mira al hombre en su realidad biológica, psicológica, social, histórica pero se preocupa, además, de su vocación sobrenatural y pone iodas las dimensiones del hombre bajo la luz de la $\mathrm{fe}^{64}$.

Ante estas opiniones hay una discrepante. Do Carmo Cheuiche se pregunta: «¿Elaboró Puebla una antropología? ¿Se puede hablar de una antropología de Puebla?» ${ }^{65}$. La respuesta que da es negativa. Sin embargo, no la fundamenta. Afirma que no hay antropología y, después, en su forma de hablar no se diferencia en nada de las opiniones anteriormente expuestas. Por eso, más bien, parece que se contradice. Comenta «que el capítulo dedicado al hombre, no va más allá de una fundamentación teológica de la dignidaḍ humana y a su luz, de la conquista de una visión cristiana del hombre» ${ }^{66}$. O sea, se busca una visión cristiana del hombre. Esto le hace coincidir con los anteriores. Además, busca el fundamento teológico de la dignidad del hombre, como punto de partida para una visión cristiana del hombre. Por otra parte, sigue insistiendo en que es necesaria una visión cristiana del hombre, para poner en claro los errores de las ideologizaciones fragmentadas, parciales e incompletas sobre el hombre que están confundiendo lás mentes de nuestro continente, con lo cual se podrá preparar el camino para la construcción de una sociedad más humana y más cristiana ${ }^{67}$.

64. «La ubicación de este párrafo dentro de la Verdad sobre el hombre en el documento de Puebla nos indica muy a las claras la relación existente entre la antropología cristiana y la intervención de la Iglesia en el plano de los derechos humanos: Toda la acción pastoral de la Iglesia tiene como trasfondo una antropología, una «concepción de la Iglesia y de la humanidad que la Iglesia tiene como propia».

Parte de una peculiar visión de fe, anclada en el misterio de Cristo, que ilumina y da sentido al misterio del hombre, con quien el Señor tiene una alianza eterna. Pero el humanismo cristiano tiene una nota sobresaliente: es integral; no admite las reducciones ni mucho menos la unidimensionalidad. $\mathrm{Y}$ así aunque mira al hombre desde la fe, no solo ve su vocación sobrenatural, sino también toda su realidad biológica, psicológica, social. Y es esta visión del hombre que posee la Iglesia, la que da más seguridad a su intervención en el campo de los derechos humanos». Cfr. J. Jiménez C., Puebla y los derechos humanos, Col Puebla, n. 23, CELAM, Bogotá 1980, p. 18.

65. A. Do CARmo Cheuiche, El hombre en Puebla, col Puebla, n. 8 CELAM, Bogotá 1979 , p. 15 .

66. Id., Ib., pp. 15-16.

67. Id., O.c., p. 16. 
Pone, por otro lado, como una de las causas de las ambigüedades en la interpretación de Medellín la ausencia de una visión cristiana sobre el hombre ${ }^{68}$. Y la Iglesia en Puebla quiere usar «el derecho y el deber de anunciar a los pueblos la visión cristiana de la persona humana» ${ }^{69}$. Porque le interesa poner en claro los criterios adecuados «para obtener una visión integral del hombre que a su vez ilumina y completa la imagen del hombre concebida por la filosofía y por las ciencias humanas» ${ }^{70}$. Esto hará que se rechacen todas aquellas concepciones antropológicas incompletas. La que nos da una visión integral del hombre es la cristiana: «La visión cristiana de la persona humana nos presenta el ser integral del hombre, exterioridad e interioridad, material y espiritual, conciencia personal y existencia social» ${ }^{71}$.

Entonces ¿qué entiende Do Carmo por antropología para firmar que no existe tal en Puebla, cuando por otra parte, está continuamente hablando de las líneas antropológicas de Puebla que, a su vez, completan e ilıminan la imagen del hombre «concebida por la filosofía y por las ciencias humanas»? ${ }^{72}$.

Quizá la solución esté en deslindar y coincidir en una definición sobre antropología. Si tratamos, simplemente de antropología filosófica, evidentemente, no podemos decir que haya una antropología en Puebla. Pero si hablamos de una visión integral del hombre, entonces sí podemos hablar de antropología en Puebla aunque con precisión de calificativos: antropología cristiana liberadora.

\section{2. ¿Cómo podríamos entender la antropología?}

Se puede preguntar por una antropología filosófica. Una aproximación para entender lo que significa sería el «recurso al análisis de las experiencias y de las situaciones humanas» ${ }^{73}$. O, quizá, desde una perspectiva más profunda, una racionalidad sobre el hombre, una «reflexión metódica y fundada sobre las dimensiones fundamentales del hombre y del sentido último de la exis-

68. Id., Ib.

69. Id., O.c., p. 19.

70. Id., O.c., p. 18.

71. Id., O.c., p. 19.

72. Id., O.c., p. 18; «...De hecho, tanto éstas como aquélla, de valor incalculable, nos hablan de cosas ciertas, absolutamente verdaderas, «respecto» al hombre, pero son incapaces de deirnos qué «es' el hombre, la dimensión integral de la persona humana. Sólo a la luz de Cristo nos es dado entender el verdadero sentido de la vida y, consecuentemente, el ser del hombre, su origen su destino") Cfr. Id., Ib. 142.

73. J. Gevaert, Antropología y catequesis, Edic. Don Bosco- CCS, Madrid ${ }^{2}$ 1975, p. 
tencia» ${ }^{74}$. Supone una función racional, crítica, creativa y metódica sobre el hombre mismo y sus dimensiones. La antropología, en otra forma aclaratoria quizá, «es la palabra que el hombre dice sobre sí mismo... que se ha hecho siempre problema de sí mismo», pero en realidad de lo que se trata es de «una reflexión científica y teórica acerca de los distintos modos históricos en que se han dado tal pregunta y tal respuesta» sobre el hiombre mismo y sus diversos aspectos en su realización histórica ${ }^{75}$. Estamos intenténdo buscar una definición que nos oriente entre tantas antropologías más 's menos delineadas que hay en la filosofía ${ }^{76}$.

Sin afiliarnos a la antropología trascendental de Coreth, nos puede ayudar con sus aclaraciones para entender lo que es la antropología filosófica. $\mathrm{Su}$ tarea «es la de abarcar y analizar la totalidad del ser humano»; por lo tanto, se trata de desarrollar sistemáticamente esa supuesta totalidad ${ }^{77}$.

Andrés Ortiz especifica y completa esta concepción de Coreth, intentando sintetizar el sentido trascendental y la realización histórica del hombre: «...ha de ser complementada por una antropología que indique las condiciones no ya de posibilidad sino de realidad y de realización del propio hombrề y su mundo», ${ }^{78}$.

Queda una pregunta latente a la cual quiere dar respuesta Coreth. ¿Cómo

74. Id., O.c., p. 14.

75. J. SPLETT, «Antropología filosófica», en Sacramentum Mundi. Enciclopedia teológiøa. I, Herder, Barcelona 1976, columna 272.

76. «No obstante estas dificultades, la cosa no es imposible. A través de las distintas antropologías se delinean algunas instancias comunes...

...Se podría afirmar que, al menos en Europa, se da una tendencia muy fuerte a superar el naturalismo, el dualismo y el individualismo, que se reflejan en la definición del hombre como 'animal racional'. En lugar de pensar en el hombre, ante todo, como una realidad «per se stans» y cerrada (una conciencia y un cuerpo animal) se tiende a definirlo en función de sus relaciones, en especial las que tiene con las demás personas y con el mundo material. Se prefiere, por eso mismo, definir al hombre como una persona que existe junto con otros hombres corporalmente en el mundo para realizarse. En lugar del concepto estático de la naturaleza humana, se acentúa su dimensión dinámica, libre, histórica; en lugar del hombre-isla, se insiste en la comunión constitutiva con otros; en vez del hombre separado de su cuerpo y en conflicto fundamental con la materia, se acentúa la dimensión corporal de su existencia y se subraya el valor positivo del cuerpo y del mundo material para la realización del hombre en la historia; en vez del hombre que sobresale y emerge de la naturaleza por su inteligencia, se prefiere ver al hombre orientado hacia la naturaleza, confiriéndole a la misma una significación humana; en lugar del pasado, que aparecía como la realización perfecta del hombre, se atribuye ahora la primacía al futuro hacia el que el hombre se orienta perfeccionándose y proyectándose...». Cfr. J. GeVAERT, O.c., pp. 18-19.

77. E. CORETH, ¿Qué es el hombre? Esquema de una antropología filosofica, Herder; Barcelona 1976, p. 33.

78. A. Ortiz-Oses, Presentación en E. Coret, O.c., p. 18. 
se puede desarrollar la totalidad del ser humano sistemáticamente? ¿Cómo se hace una antropología filosófica? Supone, al menos, un método, una hermenéutica, uná teoría del conocimiento, una ontología sobre el hombre. Es necesario tener en cuenta estos presupuestos, porque ya hace tiempo que, el nombre de antropología, ha dejado de pertenecer al ámbito puramente filosófico. Se habla por ejemplo de una antropología social, cultural, psicológica, pedagógica, biológica, religiosa ${ }^{79}$. Las ciencias particulares que añaden la connotación antropológica, presuponen un concepto del hombre y se dedican a estudiar un aspecto muy concreto del hombre. Sin embargo, quien da los criterios para definir y juzgar sobre la totalidad del ser humano, es la filosofía. Y de esa reflexión sobre el ser del hombre, saldrán a la luz los perfiles más importantes de una imagen del hombre filosóficamente razonada ${ }^{80}$.

Para llegar a sentrar la antropología de Puebla podemos tener en cuenta, también, lo que pudiera entenderse por antropología bíblica. Tendremos que partir de la revelación en la Biblia del concepto de hombre situado, pero con relación a Dios; desde y ante Dios o alejado de Él. Esto supone la afirmación de ciertas verdades sobre el hombre, con pretensión de obligatoriedad, puesto que «por primera vez y sólo ahí, se lleva al hombre a un conocimiento experimental de su propia (concreta e histórica) esencia, la cual de otro modo quedaría oculta para él» ${ }^{81}$. Si tuviéramos que resumir al máximo los temas esenciales se podría decir que, en el Antiguo Testamento, se presenta al hombre, en primer lugar, como imagen y semejanza de Dios, como el todo personal, la relación con Dios como miembro que vive en la alianza, el carácter creado, la responsabilidad, la conciencia del pecador y la esperanza de salvación en el

79. E. CORET, O.c., p. 32.

80. J. Bada Panillo, L. Betes Palomo, A. Ruiz Diaz, 3. El hombre. Edit. Verbo Divino, Estella (Navarra) ${ }^{2}$ 1979, p. 55; J. Gevaert, Antropología y catequesis, Edic. Don Bosco - CCS, Madrid $^{2}$ 1975, p. 19.

81. "Ahí el hombre es descrito como un ser incomparable: es sujeto en grado tan alto, que actúa como socio de Dios y que, frente a él, todas las demás cosas en su propia y verdadera esencia son solamente mundo circundante. Esta subjetividad como espíritu, libertad y eterna importancia individual ante Dios, como capacidad para una relación auténticamente dialogística de «alianza» hasta la absoluta proximidad en el «cara a cara» y hasta la «participación en la naturaleza divina» $\mathrm{y}$, finalmente, como la posibilidad de ser manifestación de Dios (encarnación), convierte al hombre en una realidad que en último término no es parte de un gran todo (mundo), sino que es el todo en una forma cada vez singular, lo convierte precisamente enpersona, en existencia, a diferencia de lo que está meramente presente; en tal manera que la historia única (no cíclica) del cosmos constituye un momento en la historia entre Dios y el hombre, no viceversa, y que en consecuencia, el mundo es solamente la preparación de la posibilidad de la historia del hombre (y de los ángeles), de modo que ésta es el fundamento que lo hace posible (el fin del cosmos está determinado por la historia del hombre ante Dios). Cfr. K. RAHNER, «Antropología teológica», en $S a-$ cramentum Mundi, Herder, Barcelona 1976, colum. 286-287; R. PESCH, «Antropología bíblica», en Sacramentum Mundi, I, Herder, Barcelona 1976, colum. 277-278. 
hombre. El Nuevo Testamento recoge los temas del Antiguo pero «en la persona de Jesucristo el que preferentemente ocupa el puesto central es el hombre; en él está presente el «nuevo hombre» de las promesas, la cabeza de un nuevo cuerpo de la humanidad» ${ }^{82}$. El pecado y la redención están en el centro del problema sobre el hombre.

Por otra parte, lo que pudiéramos llamar antropología teológica, parece que no está suficientemente desarrollada como para poderla delimitar adecuadamente ${ }^{83}$. Lo que está claro es que toda teología supone una concepción del hombre, es solidaria con una determinada antropología ${ }^{84}$. Una aproximación para entender la antropología teológica sería presentarla - según Watte citando a K. Rahner- como «la inclusión de todas las antropologías legítimas y limitadas en el misterio de Dios y del Verbo de Dios hecho carne» ${ }^{85}$. Supondrá una reflexión sistemática sobre las diversas concepciones sobre el hombre - aunque selectiva - a la luz de la antropología bíblica, a là luz de Dios y de Jesucristo, a la luz de la tradición cristiana histórica y escatológica.

\section{Entonces ¿hay una antropología en Puebla y qué tipo?}

Es claro que los obispos hablan como maestros de la verdad, tal como se nos dice en Puebla - título de la sección sobre el hombre- y, quieren decir la verdad, sobre el hombre concreto latinoamericano ${ }^{86}$. Su fundamento está en las enseñanzas bíblicas sobre el hombre y en la doctrina de la Iglesia, por una parte, $y$, por otra, en las adquisiciones de las ciencias y de la filosofía sobre el hombre que a la luz de la razón y de la fe son correctas. Se quiere decir la verdad sobre el hombre. En ese sèntido podemos llamarla antropología, así como lo hacen la filosofía y las otras ciencias, cuando hablan sobre el hombre, según vimos. Pero, ¿qué tipo? No hace una reflexión filosófica sobre el hombre simplemente, por tanto, no es antropología filosófica; ni tampoco es antropología bíblica, porque no repite, sin más, la concepción bíblica, aunque ella sea su fundamento. Tampoco es una antropología teológica ya que no es una reflexión metódica y sistemática a la luz de la fe ${ }^{87}$. No hace teología ni filosofía

82. R. PESCH, O.c., colum. 281.

8.

83. F. GABORIAU, El giro antropológico de la teología de hoy, Herder, Barcelona 1970, p.

84. J. Gevaert, O.c., p. 11.

85. P. WATTE, Antropología teológica y hamartiología en el siglo $X X$, en H. VORGRIMLER y otros, La teología en el siglo XX, III, BAC, Madrid 1974, p. 47; E. VolANTE, El hombre. Confrontación: Marcuse-Moltmann, Edit. Sal Terrae, Santander 1978, pp. 8-9.

86. Puebla, nn. 304-339.

87. J. Hoyos VASQUEZ, «La imagen del hombre en Puebla», en Theologica Xaveriana, 51 (1979) 152. No hace teología de escuela. En este sentido entendemos que no hace teología Puebla 
de escuela, ni se afilia a un sistema teológico o filosófico - lo cual no quiere decir, sin más, que no haga teología-, sino que los obispos, con el título de maestros de la verdad, quieren exponer al pueblo latinoamericano, las verdades fundamentales sobre el hombre a la luz de la fe. Por eso, podemos llamarla antropología cristiana. Dan la visión cristiana sobre y para el hombre latinoamericano. Pero, además, dadas las circunstancias en que habla al hombre concreto latinoamericano, en una situación especial marcada por la necesidad de liberación total, Puebla insiste en la necesidad de decir la verdad liberadora sobre el ser del hombre y su realización histórica ${ }^{88}$. Entonces, podemos calificar a esta antropología de salvación y liberación total cristiana. A Puebla le interesa decir la verdad sobre el hombre para salvarlo y liberarlo en todas las dimensiones a la luz de la revelación cristiana ${ }^{89}$. Es el primer documento eclesiástico que se plantea, directamente, el problema de decir la verdad sobre el hombre. $\mathrm{Y}$, lo hace, para evitar las ambigüedades que propició Medellín por no presentar explícitamente una visión cristiana del hombre ${ }^{90}$.

Todos entenderemos que el magisterio eclesiástico da pautas que después, en las diversas lecturas o interpretaciones, originarán las distintas teologías o filosofías ${ }^{91}$. Puebla toca los puntos fundamentales sobre el hombre, sobre su ser y su realización histórica. Por eso, merece la pena señalar los aspectos principales de esta antropología cristiana de liberación total de Puebla, pues, evidentemente, está dando origen al afianzamiento de diversas teologías o filosofías ${ }^{92}$.

"o sea, una reflexión sistemática (de algún modo) sobre Jesús y su experiencia humano-religiosa a base de filosofías, las culturas y la mentalidad en general de las distintas épocas y lugares». Cfr. A. Turrado, «De Juan XXIII a Juan Pablo II...», en Rev. Agust. de Espiritualidad, nn. 61-62 (1979) 27-28.

88. Puebla, nn. 304-305.

89. Id., n. 163.

90. A. Do CARmo Cheuiche, El hombre en Puebla, Col. Puebla, n. 8, CELAM, 1979, pp. 7-8; A. López Trujillo, Meditaciones sobre Puebla, en Puebla. Grandes Temas. I Parte, 38/CELAM, Bogotá, p. 7; D. KAPKIN, Reflexión sobre el marco doctrinal del documento de Puebla, Col. Puebla, n. 9.1, p. 20.

91. L. Boff, Lectura del documento de Puebla... Bogotá, 1980, pp. 21-29.

92. G. GutiérRez, «Pobres y liberación en Puebla», en Rev. Páginas, CEP, Lima v.IV, 2122 (1979) $17-22$. 
El método es inductivo-deductivo. En la primera parte del documento presenta la situación por la que atraviesa el ser humano y la hace suya:

Compartimos con nuestro pueblo otras angustias que brotan de la falta de respecto a su dignidad como ser humano, imagen y semejanza del Creador y a sus derechos inalienables como hijos de Dios ${ }^{93}$.

El análisis de la situación lo hacen los obispos «con ojos de fe y corazón de Pastores», no mediante análisis que correspondan a métodos de sistemas o ideologías ${ }^{94}$. Por eso, esta situación la calificarán de pecado contra el hombre, contra la dignidad humana, contra Dios de quien es hijo y está constituido a su imagen y semejanza. Destruye la vida divina en el hombre y es el mayor daño que puede hacerse, tanto a nivel personal como a nivel social, porque en último término destruye la redención por la cual dio la vida Cristo ${ }^{95}$. Es, además, la Iglesia solidaria en la encrucijada histórica por la que atraviesa el pueblo de esta parte del Continente ${ }^{96}$.

No se contenta, no obstante, con denunciar una situación infrahumana que está destruyendo al ser del hombre, sino que lo que importa, al detectar la realidad con ojos de fe, es ver la forma de salvar, liberar a América Latina ${ }^{97}$. No una América Latina en abstracto, sino teniendo como telón de fondo al propio hombre latinoamericano, con sus aspiraciones y sufrimientos.

Pero, ¿cómo la Iglesia realizará la salvación y los caminos de liberación? Aquí viene el segundo momento del método: diciendo la verdad que es propia de la Iglesia sobre Cristo, sobre la Iglesia, sobre el hombre.

Esto conducirá a:

...llevar la Buena Nueva a todos los hermanos, especialmente a los pobres y olvidados. Esta tarea evangelizadora nos conduce a la plena conversión y comunión con Cristo en la Iglesia; impregnará nuestra cultura; nos llevará a la auténtica promoción de nuestras comunidades y a una presencia crítica y orientadora ante las ideologías y políticas que condicionan la suerte de nuestras naciones ${ }^{98}$.

La hermenéutica es propia. Se da una visión cristiana sobre el hombre que tiene como acompañante la luz de la razón. Sin embargo, la luz definitiva que ilumina, critica y juzga es la luz de la fe que tiene como fundamento y modelo orientador y liberador al mismo Cristo actuante en la historia ${ }^{99}$.

93. Puebla, n. 40.

94. Id., n. 163.

95. Id., n. 330.

96. Id., n. 162 .

97. Id., n. 163.

98. Id., n. 164.

99. Id., nn. 305, 331-334. 
La ontología de esta antropología se fundamenta en Dios ${ }^{100}$. El hombre es imagen y semejanza de Dios porque así lo ha querido crear Dios y, además, nos ha hecho hijos suyos, hermanos de Cristo ${ }^{101}$. Aquí se fundamenta en última instancia, el contenido específico de esta antropología cristiana de liberación total. A partir del cual, ilumina y completa los aportes positivos de las ciencias y de la filosofía. Sobre el ser imagen de Dios se apoyan los dos pilares de la concepción antropológica de la visión cristiana sobre el hombre en Puebla: el ser del hombre y su realización histórica ${ }^{102}$.

La realización histórica complementa a la ontología antropológica. La antropología necesita ser completada «con la realidad y la realización del propio hombre y su mundo» ${ }^{103}$. El hombre no se queda en él mismo, sino que es parte fundamental de él, realizar la historia, «conducir la historia hacia la manifestación definitiva de ese Dios, que difunde su bondad para alegría eterna de sus hijos en un Reino que ya ha comenzado» ${ }^{104}$.

No nos detenemos a hacer una síntesis de la antropología de Puebla dado que ya se desprende de lo expuesto en la primera parte de este capítulo. Con lo cual creemos que queda claro lo que nos proponíamos: hay una antropología en Puebla pero con adjetivaciones; una antropología o una visión cristiana de liberación total del hombre ${ }^{105}$. Además de presentar un método, una her-

100. E. SCHILlEBEECKX, Interpretación de la fe. Aportaciones a una teología hermenéutica y crítica, Sígueme, Salamanca 1973, pp. 53-60; H.-G. GADAMER, Verdad y método. Fundamentos de una hermenéutica filosófica, Sígueme, Salamanca, 1977, pp. 526-585.

101. Puebla, nn. 40, 306, 331.

102. ID., n. 305 .

103. A. Ortiz-Osés, Presentación, en E. Coret, ¿Qué es el hombre?. Herder, Barcelona 1976, p. 18; A. ORTIZ-OsÉs, Mundo, hombre y lenguaje crítico, Sígueme, Salamanca 1976, pp. 211-232.

104. Puebla, n. 331.

105. «La palabra 'liberación', como si, por sí sola, fuese ambigua, viene generalmente acompañada de un adjetivo: 'integral' (nn. 141, 321, 475, 480, 696, 895, 1134), 'total' (n. 26), 'verdadera' (nn. 281, 452, 491, 979), 'verdadera e integral' (n. 189), 'cristiana' (nn. 481, 488, 489), 'genuina y cristiana' (n. 1026). Lo que significa que hay liberación 'parcial', 'falsa', 'no cristiana'... El Documento trata entonces de exponer lo que entiende por 'liberación en Cristo':

a) Su contenido: ...1) la liberación de todas las sevidumbres del pecado personal y social, de todo lo que desgarra al hombre y a la sociedad y que tiene su fuente en el egoísmo y en el misterio de iniquidad; 2) una liberación para el crecimiento progresivo en el ser, por la comunión con Dios y con los hombres, que culmina en la perfecta comunión del cielo (n. 482).

b) Su extensión: esta liberación abarca las diferentes dimensiones de la existencia: lo social, lo político, lo económico, lo cultural y el conjunto de sus relaciones: en todo debe circular la riqueza transformadora del Evangelio, con su aporte propio y específico (n. 483).

c) Su fundamento: ...la verdad sobre Jesucristo, la verdad sobre la Iglesia y la verdad sobre el hombre (n. 484). 
menéutica y una ontología que definen el tipo de antropología, abarca las dimensiones fundamentales de toda antropología, pero añadiendo la dimensión trascendente, relacional con Dios. Quiere hablar a partir del ser del hombre y de su realización histórica. Y, toca la dimensión del ser humano en sí; la dimensión corporal, espíritual, libre y liberadora del hombre; la dimensión interpersonal y social; la dimensión histórica del hombre en el mundo; la dimensión trascendente y escatológica.

En realidad, es una síntesis de la antropología eclesial que estudiamos en los documentos anteriores a Puebla, en el primer capítulo ${ }^{106}$. Pero, recalca el lugar desde donde se habla y a qué hombre ${ }^{107}$. Al mismo tiempo, matiza la tendencia liberadora purificándola de ideologizaciones y centrándola con las adquisiciones positivas de las ciencias y de la filosofía, en una perspectiva evangélica ${ }^{108}$.

Así, nos da motivo para denominar a la visión del hombre en Puebla, como antropología cristiana de liberación integral o total.

d) Su posible mutilación: ...si no llegara a la liberación del pecado con todas sus seducciones e idolatrías...

e) Sus medios: esta liberación cristiana usa medios evangélicos y no acude a ninguna forma de violencia ni a la dialéctica de la lucha de clases. Cfr. B. KLOPPENBurG, Evangelización y promoción humana, Col. Puebla, N. 11, CELAM, Bogotá 1979, pp. 37-38.

106. R. ORTẸGA, La gran noticia, Bogotá 1979, pp. 29-48.

107. R. ANTONCICH, La educación para la justicia... en CIEC, Metodología de una educación en y para la justicia, Bogotá 1980, pp. 55-67.

108. «La síntesis se operó con la continua acentuación de los dos polos: liberación sí, derechos humanos sí, dimensión política de la fe sí -como quiere una tendencia - pero desde la fe, desde el Evangelio, desde la adhesión inequívoca de la totalidad de la doctrina católica - como quiere la otra tendencia» Cfr. L. BofF, Lectura del documento de Puebla desde América Latina creyente y oprimida, Indo-Américan Press Service, Bogotá 1980, p. 20; «Después, en el n. 545, hace nota el riesgo de ideologización a que se expone la reflexión teológica, cuando se realiza partiendo de una praxis que recurre al análisis marxista, denunciando entonces sus tres graves consecuencias: 1) la total politización de la existencia cristiana; 2) la disolución del lenguaje de la fe en el de las ciencias humanas; 3) el vaciamiento de la dimensión trascendental de la salvación cristiana.

...Nuestra tarea es la de servir a la verdad y a la justicia en las dimensiones de la 'temporalidad' humana, pero siempre dentro de una perspectiva que sea de la salvación eterna». Cfr. BV. KLOPPENBURG, O.c., pp. 39-40; S. SABUGAL, ¿Liberación y secularizacion? Intento de una respuesta bíblica, Herder, Barcelona 1978, pp. 7-310; H. AlesSANDRI, La liberación cristiana, Col. Pueblą, n. 11, CELAM, Bogotá 1979, pp. 7-14; J.L. IDIGORAS, «La liberación en Púebla», en Rev. Teol. Limense, vol. XIII, 3 (1979) 317-324; F. INTERDONATO, Teología latinoamericana ¿Teología de la liberacion»», Edic. Paulinas, 1978, pp. 154-155; A. LoPEZ Trujillo, Perfiles de Puebla, Col. Puebla, n. 3, Bogotá 1979, pp. 49-68; V. ZEA, «Puebla: Cristología y liberación», en Theol. Xaver. 51 (1979) 115-116; J.A. VELA, Proyecto educativo de la Escuela Católica en América latina, Indo-American Press Service, Bogotá 1980, pp. 66-92. 


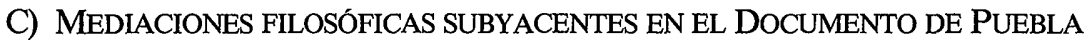

Nos referimos a las mediaciones de antropología filosófica que utiliza Puebla, en la expresión de su visión sobre el hombre. Para poder encontrar las filosofías subyacentes, tendremos que partir de las mediaciones, en la adaptación que quiere del mensaje al hombre latinoamericano. A su vez, estas adaptaciones tienen como marco de fondo aunque por encima, unas teologías. Y es que no háy teología que no presuponga actualmente una antropología filosófica, ya sea fenomenológica existencial, marxista, estructural ${ }^{109}$. Este análisis nos llevará al diagnóstico sobre el tipo de antropología filosófica subyacente en Puebla.

\section{El Magisterio eclesiástico hace teología o filosofía en Puebla}

Al magisterio eclesiástico, en cualquiera de sus facetas, se le plantea el problema hermenéutico, el problema de interpretación y expresión del mensaje de Dios para comunicárselo al hombre de hoy ${ }^{110}$. No hace teología ni filosofía porque ese es "el estilo propio del magisterio que consiste en afirmar las verdades, sin explicarlas a la manera de un profesor; poner en movimiento la teoría, la teología, sin hacer el mismo propiamente teoría...» ${ }^{111}$.

Sin embargo, el magisterio habla de lo concerniente a Dios. Intenta comprender y explicar el lenguaje de Dios y, al mismo tiempo, transmitir el sentido comprensible para los hombres en cada época histórica. Y, evidentemente, se le plantea, al instante, el problema de la intelección, del lenguaje y de la mediación ${ }^{113}$. Con esto, se hace presente, también aquí, la cuestión hermenéutica. Supone interpretación y actualización; criterios de interpretación y mediación para la transmisión ${ }^{114}$. En toda hermenéutica subyace una filoso-

109. P. WATTE, «Antropología teológica y hamartiología en el siglo XX», en H. VORGRIMLER y otros, La teología en el siglo XX, BAC, Madrid 1974, pp. 47-63; J.P. RESWEBER, La Theologie Face au défi hermeneutique, Louvain, Vander, 1975, pp. 238-262; J. GEvAERT, Antropología y catequesis, Madrid ${ }^{2}$ 1975, p. 11; E. CHIAVACCI, Teologia morale. Morale generale, Cittadella Editrice, Assi 1977, pp. 11-26.

110. R. ANTONCICH, Hacia una mejor lectura de los documentos sociales del Magisterio, Pontificia Universidad Católica del Perú, Departamento de Teología, Lima, pp. 47-61 (Mimeografiado); Id., «Notas para una lectura latinoamericana de la encíclica Redemptor Hominis, en Rev. Páginas, Separata, vol. IV, 26 (1979) 2-3.

112. F. InTERdonato, La sacramentalización y Puebla, Col. Puebla, n. 17, CELAM, Bogotá 1980, pp. 21-22. 62.

113. E. CORET, Cuestiones fundamentales de hermenéutica, Herder, Barcelona 1972, p. 31-

114. R. MARLE, Hermenéutica y catequesis, Barcelona 1973, p. 23; M. WILES, Del Evange- 
fía, una mediación filosófica ${ }^{115}$. El magisterio eclesiástico, está sin duda, por encima de cualquier sistema, teológico o filosófico, pero, en realidad, ante la situación de tener que utilizar la mediación más conveniente, para expresar las verdades cristianas, se ve ante la necesidad de la elección. Le toca tomar, no sistemas, sino el lenguaje que refleja las adquisiciones universales válidas que se han originado de esos sistemas teológicos o filosóficos.

En el Vaticano II subyace una orientación existencial-personalista, proveniente de la teología, promovida por los teólogos principales que influyeron en la orientación del Concilio. Fundamentalmente subyace a su teología la corriente existencial-personalista con diversas ramificaciónes, pero, en relación o dialéctica, más o menos cercana o distante de la escolástica ${ }^{116}$. También citamos, al estudiar la «Populorum Progressio», a los principales asesores de Pablo VI, que allí dejaron su huella en la concepción del hombre ${ }^{117}$. El mismo Papa $_{4}$ Juan Pablo II hace alusión a la orientación personalista, como mediación hoy, cuando dice que conviene profundizar y aclarar «cada vez mejor los fundamentos bíblicos y las razones «personalistas», como hoy se dice...» ${ }^{118}$.

lio al dogma , Edic. Cristiandad, Madrid 1974, p. 123-136; D. ANTISERI, El problema del lenguaje religioso. Dios en la filosofía analítica, Edic. Cristiandad, Madrid 1976, pp. 25-30; P. EICHER, «La revelación 'administrada'. Relación entre la Iglesia institucional y la experiencia», en Rv. Concilium, 133 (1978) 318-322; B. van IERSEL, «El exegeta y la lingúística», en Rev. Concilim, 135 (1978) 240-244; F. Bussini, «Desplazamientos de la teología y nueva configuración de la catolicidad de la Iglesia», Ib., pp. 193-208; B. MONDIN, ¿Cómo hablar de Dios hov? El lenguaje teológico, Edic. Paulinas 1979, pp. 53-70.

115. «Por hermenéutica y por la actividad y ciencia que así se denomina queremos designar, pues, la ciencia eminentemente bíblico-filosófica que procura la captación del sentido o signiirado que tiene para el hombre la Palabra de Dios». Cfr. A. PARRA, Fe e interpretaciones de la $\therefore$ Una introducción a la Hermenéutica teológica, Bogotá, 1976, p. 24.

116. Aunque no se adscribe a una filosofía ni a una teología porque es un documento eclesiásticc sin embargo, escribe su mensaje con mediaciones de rasgos teológicos y fílosóficos que toma de las corrientes que predominan. El lenguaje es de esas corrientes para expresar un mensaje que no quiere encasillarse, pues está por encima de las corrientes. «El Vaticano II..., comienza a sustituir esa mentalidad greco-romana por la que impone el personalismo evangélico y el personalismo y universalismo de las ciencias humanas actuales, es decir, por una teología de relaciones interpersonales entre Dios y los hombres. Además de ese universalismo de la magna historia de salvación, cuyo signo por excelencia es la «comunión» de los seguidores de Cristo o Iglesia cristiana, como una ayuda para la vida y la salvación de los fieles y no como un estorbo para los que no lo son (Constitución sobre la Iglesia, n. 16; Const. «Gaudium et Spes», nn. 12-17, 22), su defensa de la fe o su apologética ya no es aquella serie de argumentos..., sino que es ante todo una apologética del testimonio...» Cfr. A. Turrado, «De Juan XXIII a Juan Pablo II. Reflexiones en torno a la raíz de sus posturas doctrinal y práctica, en Revista Agustiniana de espiritualidad, vol. XX, nn. 61-62 (1979) 55. Los teólogus que más influyeron en el Vat. II, fưeron los que están alrededor de la llamada «Nueva Teología». Cfr. T. Pérez, 18 propulsores del Concilio, Edic. Paulinas, Bilbao, 1966. Fabro los llama los «de la teología progresista». Cfr. C. FABRo, La aventura de la teologia progresista, Pamplona 1976.

117. A. LÓPEZ, El hombre un ser integral, Paulinas, Bogotá 1973, pp. 11-12.

118. Juan Pablo II, «Discurso de clausura del Sínodo de los obispos», (25-10-80), n. 8. 
A la Iglesia, que tiene la obligación de transmitir el Evangelio a los hombres, le debe preocupar cómo es el hombre, cuáles son sus conceptos e, inclusive, su saber filosófico y cuál es el lenguaje más adecuado para llegar a él. El Vaticano II ha centrado muy acertadamente estas ideas sobre las mediaciones ${ }^{119}$.

Evidentemente, queda claro lo que nos interesa resaltar, o sea, en el magisterio de la Iglesia hay huellas de teologías, y, a su vez, éstas tienen como substrato filosofías y, en nuestro caso, rasgos de antropologías filosóficas que ayudan a especificar la verdadera imagen del hombre, al mismo tiempo que dan pie para nuevas elaboraciones teológicas y filosóficas ${ }^{120}$.

Hace una aclaración importante la Congregación para la doctrina de la fe:

En fin, las verdades que la Iglesia pretende enseñar realmente por medio de fórmulas dogmáticas, son sin duda distintas de las condiciones cambiantes propias de una época determinada; pero no se excluye que ellas estén eventualmente formuladas, aun por el Magisterio, en términos en que se advierten huellas de tales concepciones ${ }^{121}$.

Bajo este critero podemos considerar a Puebla. Aunque no trata de definir verdades dogmáticas, sin embargo, quiere decir la verdad sobre Cristo, la Iglesia y el hombre, para el cristiano latinoamericano y para el hombre de buena voluntad. Son los pastores que se dirigen a sus fieles, para poner en claro los puntos que consideran importantes, especialmente, el que nos interesa a nosotros: la verdad sobre el hombre. En este caso, el Papa, en el discurso inaugural, les recuerda el deber de ejercitar su título de Maestros de la verdad. Especifica qué tipo de verdad; no humana y racional simplemente, «sino de la verdad que viene de Dios; que trae consigo el principio de la auténtica libera-

119. «Gaudium et Spes», nn. 6-8, 44.

120. «...si se tiene en cuenta el lugar central de la antropología en la doctrina y en la praxis de la Iglesia después del Vaticano II. Teología, catequesis y pastoral descubren con sus nuevos conocimientos que la credibilidad y la honradez de la predicación están condicionadas..., por la imagen del hombre subyacente bajo la doctrina y la praxis...» Cfr. J. GevaerT, Antropología y catequesis, Madrid 1975, p. 7. Llega a afirmar que toda catequesis es solidaria con una determinada antropología. Cfr. Id., O.c., p. 11; «La antropología filosófica, al presentar una imagen más adecuada del hombre, constituye constantemente una norma negativa o, en todo caso, una instancia crítica para la predicación del Evangelio, en cuanto advertencia para no atenerse a imágenes del hombre, que estén en contraste con las verdaderamente probadas y fundadas sobre las ciencias y el pensamiento filosófico moderno». Cfr. Id., O.c., p. 11; «Una severísima crítica de la religión proviene hoy de las ciencias del hombre... Se tiene todo el interés en conocer estas críticas y en escucharlas para purificar nuestro modo de vivir la fe». Cfr. R. CoFFY, «Théologie et anthropologie,» en Catéchese, 8 (1968) 327.

121. Declaración «Mysterium Ecclesiae» de la Sagrada Congregación para la doctrina de la fe, 24 de junio de 1973. 
ción del hombre..., esa verdad que es la única en ofrecer una base sólida para una "praxis adecuada» ${ }^{122}$. Al hacer estas acotaciones el Papa, en ellas mismas, ya se reflejan ciertas connotaciones filosóficas.

A Puebla le toca de lleno el problema de las mediaciones y - según pienso que se podría llamar- el de la espiral hermenéutica.

\section{Mediaciones y espiral hermenéutica}

Da oportunidad a dos puntos: las mediaciones que utiliza y las lecturas a qué da lugar.

Parte desde Latinoamérica como lugar teológico y filosófico ${ }^{123}$. Puebla se dirige al hombre latinoamericano de hoy y tiene que hacerlo, de tal forma, que la entienda, al mismo tiempo, que no desvirtua el mensaje de Dios ${ }^{124}$. Tiene que tener una intelección adecuada del mensaje y expresarlo en palabras comprensibles al hombre de América Latina ${ }^{125}$. pero, las palabras no son independientes; suponen un uso dentro de sistemas. Nos referimos, sin más, al contexto en el cual se utilizan estas palabras.

Para poder hacerse entender en lenguaje religioso hay que plantearse el problema hermenéutico. En Puebla ya lo hemos visto. Pudiéramos calificar de espiral hermenéutica lo que hace Puebla; la filosofía y las ciencias humanas - se trata de la visión que dan sobre el hombre-, a la luz de la razón y la fe. Ver en la fe, consistirá en descubrir sobre el tiempo la paralela de la eternidad. La espiral antropológica de Puebla estará en:

...visualizar la realidad viva que existe ahí, no a partir de esquemas de ideologías constituyentes o emergentes, sino desde el ángulo de la visión del designio divino respecto al hombre y su realización histórica... Cristo es el medio, es decir, nos ofrece los criterios fundamentales para «juzgar» la realidad ${ }^{126}$.

122. JuAn Pablo II, Discurso inaugural de Puebla, I.

123. H. AlesSANDRI, Eclesiología, Col. Puebla, n. 6.1, CELAM, Bogotá 1979, pp. 7-8.

124. E. SCHILLEBEECKX, Interpretación de la fe. Aportaciones a una teología hermenéutica y crítica, Sígueme, Salamanca 1973, pp. 15-20; H. KunG, ¿Existe Dios? Respuesta al problema de Dios en nuestro tiempo, Edic. Cristiandad, Madrid ${ }^{2}$ 1979, pp. 19-23.

125. B. MoNDIN, Il problema del linguaggio teologico dalle origini a oggi, Brescia ${ }^{2} 1975$, pp. 5-14; Id., Cómo hablar de Dios hoy? Edic. Paulinas, Madrid 1979, pp. 6-7; A. GRABNERHAIDER, Semiótica y teología. El lenguaje religioso ante la filosofía analítica y hermenéutica, Edit. Verbo Divino, Estella (Navarra) 1976, pp. 175-258; A. RINCÓN, «Lenguaje religioso y ciencias del lenguaje,» en Rev. Thel. Xaveriana, 28, n. 3 (1978) 395-411; J. SADABA, Filosofía, lógica, religión, Sígueme, Salamanca 1978, pp. 10-11; J. AlLIENDE, Religión popular en Puebla: la madurez de una reflexión, en Puebla. Grandes temas, I Parte, 38/CELAM, Bogotá, pp. 262-263; H. AlessANDri, Eclesiología, Col. Puebla, n. 6.1, CELAM, Bogotá 1979, pp. 7-8.

126. A. Do CARMo Cheuiche, El hombre en Puebla, Col. Puebla, n. 8, CELAM, Bogotá 1979, pp. 12-13. 
La espiral hermenéutica comienza en la constatación de la situación del hombre, no a partir 'de análisis dependientes de sistemas, sino aprovechando los aportes de las ciencias y la filosofía, pero desligando los hechos constatados por las ciencias y la filosofía, sin adherirse a los sistemas de los cuales provienen. La luz, el criterio orientador bajo el cual se mira esa situación, es la fe y esa fe tiene como máximo criterio al mismo Cristo. Aquí, avanza la espiral hacia la realización histórica del hombre, dinamizada por la fuerza vital, por el amor originado en Cristo. A partir de aquí, se provoca, a su vez, de nuevo la continuación de la espiral siguiendo estos pasos impulsados por la dialéctica del amor.

Ya tenemos por donde va la espiral hermenéutica. Ya sabemos bajo qué luz se mira. Esto tendremos que tenerlo en cuenta para saber en qué sentido; Puebla, utiliza las palabras de que se sirve como mediación para expresar un mensaje. No quiere decir por tanto, que, al utilizar unas palabras, se valga, sin más, de un sistema filosófico para transmitir el mensaje. Esas palabras hay que entenderlas en el contexto de la luz de la razón, pero iluminada sobre todo por la fe, teniendo como culmen criteriológico al mismo Cristo ${ }^{127}$.

\section{a) Mediaciones de sistemas que explícitamente rechaza}

Hay antropologías que son directamente rechazadas en Puebla, por ser consideradas como visiones del hombre, incompletas e inclusive nocivas, dado que parcializan o deforman la visión integral del hombre y, por supuesto, dejan de lado la dimensión trascendente o la desvirtúan ${ }^{128}$. Son visiones inadecuadas del hombre en América Latina según las categorías de Puebla la visióndeterminista; la psicologista; las visiones economicistas como aparecen en el hombre consumista, en el liberalismo económico o en el marxismo materialista ateo; la visión estatista y la visión puramente cientista ${ }^{129}$.

Sin embargo, hay que tener en cuenta un aspecto de suma importancia. Puebla va a utilizar algunas palabras de estos sistemas, pero, ya esclarecimos, que no dentro del contexto de los mismo sistemas, sino a la luz de la razón e iluminadas por la fe. El significado que tienen las palabras en los sistemas de origen, adquirirán un sentido pleno $\mathrm{y}$, pudiéramos decir ortodoxo, en la utilización que hace Puebla de ellas. Por tanto, el usar una palabra no quiere decir que consagre un sistema, sino que hay que interpretarla en el contexto que le da Puebla para esclarecer el mensaje sobre el hombre de hoy. Las ideologías no se pueden confundir con los movimientos originados por ellas y las adqui-

127. Puebla, nn. 304-305.

128. Id., nn. 308-315.

129. J. A. Vela, Proyecto educativo de la escuela católica en América latina, IndoAmerican Press Service, Bogotá 1980, pp. 68-70. 
siciones positivas a que dan lugar, que pasan a ser patrimonio universal. Las ideologías pueden ser erradas, sin embargo, los movimientos provenientes de ellas evolucionan y pueden transformarse en portadores de aspectos dignos de tenerse en cuenta. Esto es lo que hace Puebla. Se apropia de las adquisiciones universales engarzándolas bajo su luz, aunque rechace el sistema o ideología en la cual haya tenido su génesis ${ }^{130}$.

\section{b) Lecturas de Puebla}

Tenemos un principio claro: toda teología supone una filosofía y, en nuestro caso, una antropología filosófica. Vamos a ver las teologías que subyacen a Puebla para poder desvelar las antropologías filosóficas que presuponen.

Saltan a la vista dos tendencias principales: una que reclama para sí la ortodoxia y otra que se califica de innovadora. La primera, pudiéramos decir, se refleja en las publicaciones del CELAM, acaudilladas por Alfonso López Trujillo. La segunda sería la Teología de la Liberación, cuyos nombres sobresalientes son los de Gustavo Gutiérrez, Hugo Assman, Juan Carlos Scannone, Leonardo Boff; alrededor de ellos están, también, Jon Sobrino, Enrique Dussel, Clodovis Boff y otros ${ }^{131}$.

La lectura ortodoxa quiere enraizarse en el Concilio Vaticano II y en la doctrina de los Papas, sin descuidar la situación de América Latina y del hom-

130. Pablo VI recoge en la «Octogessima Adveniens», n. 30, el esclarecimiento que hacía yà Juan XXIII en la «Pacem in terris» sobre este punto; J.M. GoNZÁLEZ-RuIZ, Marxismo y cristianismo frente al hombre nuevo, Marova-Fontanella, Madrid 1972, pp. 20-21; J. Galat, Liberación de la liberación, Edic. Paulinas̊, Bogotá 1974, pp. 13-14; Salvador LÓPEZ, El hom'Jre oprimido, Edic. Paulinas, Bogotá 1975, pp. 7-8; A. Lopez Trujillo, Hacia una sociedad nueva, Edic. Paulinas, Bogotá 1978, pp. 19-20; Id., Meditación sobre Puebla, en Puebla. Grandes temas, I Parte, CELAM, Bogotá, p. 6. «La labor 'humanizante' y 'liberadora' de la Iglesia queda necesariamente determida en su sentido, en su dirección, en sus límites y en su meta misma por el mensaje evangélico que la Iglesia proclama, el cual traduce la maravillosa obra de Dios, poderosa y eficaz, en Jesucristo. La gran conquista de Puebla fue haber hecho claridad en este punto tan importante, con lo cual, asumiendo lo mejor de Medillín, Puebla da un paso adelante que ha de significar muchísimo para la conciencia y la práctica de la Iglesia Latinoamericana...

...La Iglesia no debe ni puede, si quiere ser fiel, si quiere ser fiel a su propia misión de obrar la salvación del mundo, contentarse o acaso resignarse con una nivelación anónima de su propia acción como «promoción humana». La promoción humana desde el Evangelio coincide explícitamente con lo que el nombre y la realidad de Jesucristo implican y entrañan; la «liberación» verdadera y auténtica no se nivela con ningún esfuerzo humano ni se extingue en ninguna forma social o política que el hombre pueda ir suscitando en el seno de la historia». Cfr. D. KAPKIN, Reflexiones sobre el marco doctrinal... pp. 19-22.

131. A. López Trujillo, Las teologías de la liberación en América Latina, en Liberación: diálogos en el CELAM, Bogotá 1974, p. 45. La primera hace sus publicaciones auspiciadas por el CELAM; la segunda, entre otras la editorial Indo-American Press Service de Bogotá ha publicado últimamente, en especial, lo referente a Puebla de estos teólogos. En Lima el CEP (Centro de Estudios y Publicaciones) publica los escritos de esta línea en el Perú. 
bre latinoamericano, a quien dirige su mensaje. Su apoyo teológico está en la llamada «Nueva Teología» que propulsó al Vaticano II. Basta analizar el «Documento de consulta a las Conferencias Episcopales» como preparación para la Tercera Conferencia General del Episcopado Latinoamericano, elaborado bajo la dirección de López Trujillo, para ver reflejado el concepto de Dios, Cristo, Iglesia de los teólogos europeos de esta corriente existencialpersonalista ${ }^{132}$. Entre los hombres que hay que destacar en la elaboración de esta orientación en Europa está Romano Guardini. Tiene mucho que ver con el pensamiento agustiniano por contrafosición al tomismo o, más bien, a la neoescolástica. Adẹmás, hay en él una declarada influencia de la corriente fenomenológica. Se baja a lo real, concreto y viviente; tiene una agudeza psicológica incomparable y se basa en un análisis fenomenológico para construir su teología. En su hablar de Dios se ve un pensamiento lleno de interés vital, de intuición, sentimiento, de experiencia religiosa por contraposición a una neoescolástica fría, abstracta, jurídica ${ }^{133}$.

Karl Adam, además del cambio que da del racionalismo neoescolástico hacia la historia, su pensamiento se apoya en la filosofía de la religión de Scheler. La neoescolástica, objetivadora y alejada del tiempo, le quitaba el espacio para las categorías y realidades puestas a la vista por la historia. El pensamiento de San Agustín también le servirá como punto de apoyo para liberarse de lo racionalista, jurídico y estático de la neoescolástica ${ }^{134}$.

M.-D. Chenu, mediante un método histórico, quiere limpiar todas las adyacencias acumụladas a través del tiempo, para dejar al descubierto el auténticò pensamiento de Santo Tomás y de los estudios medievales. Sin embargo, trabajar según el método histórico suponía «ejercer la teología en vistas al mundo y al hombre; el hombre y el mundo de hoy» ${ }^{135}$. La historicidad y la experiencia existencial subyacen a su teología, con reminiscencias de Blondel.

Sobre Ives Congar ha tenido gran influencia «las realidades terrestres» y la línea histórica de Chenu, con reminiscencias de Blondel y de la filosofía existencial. Henri de Lubac está dentro de la senda de los dos nombres ante-

132. CELAM, Documentos de consulta a las Conferencias episcopales, Puebla (México) 1978, pp.77-138; Juan XXIII puso, él personalmente, en la lista de peritos del Concilio a los principales representantes de la «nueva Teología»: M.D. Chenu, Y. Congar, H. de Lubac, K. Rahner, E. Schillebeeckx. Cfr. A. TuRrado, De Juan XXIII a Juan Pablo II, vol. XX, nn. 61-62 (1979) 24-26. 107.

133. T.M. SchOоF, La nueva teología católica, Carlos Lohlé, Buenos Aires 1971, pp. $105-$ 111.

134. T.M. Schoof, La nueva teología católica, Carlos Lohlé, Buenos Aires 1971, pp. 109-

135. Id., O.c., p. 129. 
riores y, de forma especial, Blondel ha influenciado en él, siendo precisamente de sus íntimos ${ }^{136}$.

Teilhard de Chardin, científico, teólogo, filósofo, centró su pensamiento en el «fenómeno humano», resultando una cosmovisión evolucionista de su pensamiento, que tiene a Dios como atracción total del hombre. Subyace una filosofía fenomenológica de convergencia y personalización ${ }^{137}$. En el fondo latían puntos comunes con los autores anteriores: el interés por lo dinámico, el sentido dinámico de la historia al mismo tiempo que cristiano, las relaciones entre la misión terrestre y el perfeccionamiento trascendente del hombre, entre el humanismo y el cristianismo ${ }^{138}$.

Urs von Balthasar, pensador original, tiene de fondo la fenomenología ${ }^{139}$. Bernard Häring construye su moral partiendo del existencialpersonalismo ${ }^{140}$.

Heidegger, del cual fue discípulo, y Marechal son los filósofos que subyacen claramente en la teología de Karl Rahner. No hay más que leer dos de sus libros clásicos: Espíritu en el mundo y Oyente de la Palabra. editados ambos en castellano por Herder ${ }^{141}$.

Edward Schillebeeckx, más que por las líneas de pensamiento, su relación con el anterior es por el intenso ejercicio de la filosofía y por el conocimiento de las corrientes filosóficas modernas que le valen de substrato aunque por diferentes caminos. Schillebeeckx comienza interesándose por la antropología de D. de Petter. Éste logra una síntesis interesante y original entre el tomismo y la fenomenología moderna, especialmente la de Husserl, pero sin embargo, se aparta en puntos esenciales de Marechal.

La inquietud de Schillebeeckx le hace ir más allá de Petter. Escruta todas las vías filosóficas actuales con espíritu crítico y abierto, como se puede ver en su libro: «Interpretación de la fe», por ejemplo. Se deja influenciar de una forma especial por el existencial-personalismo. En sus obras sobre los sacramentos tiene cabida especial la antropología personalista, $y$, en su cristología, subyace la personalización cósmica de Teilhard ${ }^{142}$.

Hemos echado un vistazo rápido a estos autores ya que las huellas de su

136. Id., O.c., pp. 140-144.

137. J. DE S. LUCAS, «Convergencia y personalización en la obra de P. Teilhard de Char-

din, en J. de S. LuCAS y otros, Antropologías del siglo $X X$, Sígueme 1976, pp. 62-73.

138. T.M. SCHOOF, Oc., p. 147.

139. T. PÉreZ, 18 propulsores del Concilio, Edic. Paulinas, Bilbabo, 1966, pp. 11-126.

140. T. PÉreZ, O.c., pp. 95-110; HÄrING, El personalismo, Herder, Barcelona 1965.

141. T.M. SCHOOF, O.c., pp. 156-157; VARIOS, Tendencias de la teología del siglo $X X$, Studium, Madrid 1970, p. 642.

142. Id., O.c., pp. 307-308; T.M. SCHOOF, O.c., pp. 169-172; VARIOs, Tendencias de la teología en el siglo XX. Una historia en semblänzas, Studium, Madrid 1970, pp. 751-757. 
pensamiento están en el Vaticano II. Habíamos dicho que la lectura ortodoxa tiene como fondo estas huellas. En el pensamiento de López Trujillo se nota el substrato de estos teólogos y sus filosofías orientación existencial-personalista-dialógica ${ }^{-143}$.

Esta tendencia, como dice el mismo López Trujillo, pone el acento en lo religioso sin olvido de la dimensión política pero sin privilegiarla ${ }^{144}$.

Leonardo Boff caracteriza a esta tendencia, que él llama ortodoxa, con los siguientes rasgos: Su preocupación fundamental es la recta doctrina, la conversión del corazón y las prácticas cultuales y religiosas. Se remarca la trascendencia y el compromiso de fe. El cambio social se tiende a espiritualizar. Si hay hombres convertidos, lograremos el cambio social. Este cambio se consigue a través de la introducción de los ideales y valores morales cristianos en la sociedad, por medio de la cultura más que fomentando el cambio de estructuras. «Los temas como: liberación, pecado social, conversión social de estructuras, etc., no son rechazados, sino entendidos en moldes o matrices que expresan de forma inadecuada sus contenidos históricos o analíticos y que favorecen su dimensión espiritual y metafísica» ${ }^{145}$. Critica al capitalismo y al marxismo y quiere construir una nueva sociedad sobre los valores cristianos.

La aplicación que hace esta lectura de Puebla va por los siguientes cauces: se entiende con mucha pureza el contenido doctrinal cristológico, eclesiológico y la verdad divina sobre el hombre. Comunión y participación es el «slogan» de Puebla:

...una comunión y una participación que han de plasmarse en realidades definitivas, sobre tres planos inseparables: la relación del hombre con el mundo, como señor; con las personas como hermano y con Dios como hijo ${ }^{146}$.

Leonardo Boff, con los de su línea, critican a esta orientación por considerar que se queda la lectura en una actitud espiritualizante e idealista ${ }^{147}$.

La otra lectura, a la cual Leonardo Boff denomina innovadora, la delimi-

143. A. LÓPEZ Trujillo, El hombre ser integral, Paulinas, Bogotá 1973, pp. 11-12; J. AL FARO, Cristología y antropología, Cristiandad, Madrid 1973, pp. 227-366. 413-476; W. THÜSING, Datos del Nuevo Testamento para una cristología trascendental-dialogica, en K. RAHNER W. Thüsing, Cristología. Estudio teológico y exegétido, Edic. Cristiandad, Madrid 1975, pp. 290 296; J.L. ILLANES, Sobre el saber teologico, Rialp, Madrid 1978, pp. 69-152; J. FERNÁNDES GoNZÁLEZ, Antropología y teología actual, Zamora 1978, pp. 79-98.

144. A. LÓPEZ TRUjILlo, Las teologías de la liberación en América Latina, en Diálogos en CELAM, Bogotá 1974, pp. 45-46.

145. L. BofF, Lectura del documento de Puebla desde América Latina creyente y oprimida, Bogotá 1980, p. 21.

146. PUeBla, n. 322.

147. L. Boff, O.c., p. 23. 
ta López Trujillo con los siguientes rasgos: está estructurada socioteológicamente, predominando el polo socio-político sobre el religioso aunque, por supuesto, no lo excluye. Además, tiene como medio de lectura el análisis marxista ${ }^{148}$.

Leonardo Boff, por su parte, delinea la lectura innovadora. Se preocupa de la salvación integral en lo espiritual, social, político, secular. La misión de la Iglesia es integral ya que «el Reino de Dios se encuentra en medio de nosotros» (Lc 17,21) ${ }^{149}$. La Iglesia, continuadora del proceso de la redención de Cristo, debe asumir la purificación de lo político y de los socio-histórico. «Lo que salva no son las prédicas sino las prácticas; no directamente el culto sino la ética» ${ }^{150}$. El compromiso cristiano exigirá ponerse del lado de los pobres y colaborar en la transformación de las estructuras de la sociedad para que desde la raíz salga una nueva sociedad donde se puedan vivir auténticamente los valores evangélicos.

No se trata de oponer las prácticas éticas a los deberes del culto, sino saber dar prioridades. El culto es expresión de lo que se vive en la práctica ética, donde se fundamenta la salvación. La celebración será consecuencia de la conversión que llevará a una práctica comprometida e informada por el amor ${ }^{151}$.

Aplicada esta lectura a Puebla podríamos resumirla: «La única lectura adecuada de las consignas de Puebla es aquella que tiene en cuenta el horizonte utópico, la instancia ético-crítica y asume todo esto dentro de las mediacio-

148. A. LóPEz Trujillo, O.c., pp. 45-46.

149. L. BofF, O.c., pp. 14-15.

150. Id., O.c., p. 15. El estudio más serio que se ha hecho sobre los elementos esenciales para que la Teología de la liberación sea teología, es la tesis doctoral de Clodovis Boff -hermano de Leonardo Boff-, Teologia e prática. Teologia do Politico e suas mediasoes, CID, Petrópolis 1978, p. 13-14.

151. «Es importante evitar todo reduccionismo, como nos ha llamado la atención la 'Evangelii Nuntiandi»: ni un reduccionismo religioso (EN 34) ni un reduccionismo político (EN 32). Hay que relacionar correctamente las dos instancias (EN 35) y 'esforzarse por insertar siempre la lucha cristiana por la liberación en el designio global de la salvación que la Iglesia anuncia». Cfr. L. BoFF, O.C., p. 16; Clodovis Boff, dándose cuenta de las deficiencias de ciertas teologías de la praxis o de la Liberación, hace un estudio crítico que revela fehacientemente las condiciones epistemológicas para que una tal teología, sea de hecho teología y no ideología o discurso persuasivo. Cfr. A. GeSChe, Prólogo, en CL. Boff, Teologia e práctica. Teologia do Politico e suas mediasoes, CID, Petrópolis 1978, p. 12; Leonardo Boff hace una buena presentación del intento de su hermano: «:el problema central de este método que arranca siempre de la realidad (interpretada socio-analíticamente), es cómo articular tres discursos de naturaleza diversa: el discurso socioanalítico, el discurso teológico y el práctico-pastoral. Que esto sea posible, lo mostró la elaboración teórica de la teología de la liberación que, a partir de un cierto momento de su elaboración, ha conseguido superar ya sea el teologismo (la teología como único discurso válido para pensar lo real-social), ya sea el sociologismo (las ciencias de lo social como único discurso legítimo), ya sea el bilingüismo (el paralelismo de dos lenguajes, sin articulación), ya sea la mezcla semántica (la mezcla de dos lenguajes en una articulación mal hecha». Cfr. L. Boff, O.c., pp. 32-33. 
nes histórico-sociales de prácticas que conducen a cambios reales de la situación» ${ }^{152}$. Aunque Puebla no asume la teología de la Liberación, sin embargo, hay abundantes huellas. Una muy importante es la consagración del método: situación-reflexión-acción. En la parte pastoral, cuando se olvidan de la excesiva preocupación por la ortodoxia, se consigue una lograda articulación del método ${ }^{153}$. Por otra parte, Puebla debe ser leído a la luz de una noción que impregna todo el documento: liberación integral ${ }^{154}$. Es la afirmación tajante de Gustavo Gutiérrez.

La teología de la liberación es la que subyace en la segunda lectura que propone Leonardo Boff, o sea, la lectura innovadora ${ }^{155}$. La filosofía que le vale de substrato es el marxismo ${ }^{156}$. El mismo Alfredo Fierro, simpatizante

152. L. Boff, O.c., p. 23.

153. «Pero queda constancia de la consagración del método. Inclusive se pide educar a las comunidades y personas en una metodología de análisis de la realidad, para reflexionar sobre esta realidad desde el Evangelio, y optar por los objetivos y medios más aptos y hacer de ellos un uso más racional en la acción evangelizadora (n. 1307). Los obispos hacen una confesión muy grave: desde 1955, cuando se creó el CELAM hasta hoy «la Iglesia ha ido adquiriendo conciencia cada vez más clara y profunda de que la evangelización es su misión fundamental y de que no es posible su cumplimiento sin un esfuerzo permanente de conocimiento de la realidad y de adaptación dinámica, atractiva, convincente del Mensaje a los hombres de hoy» (n. 85). Cfr. L. BofF, O.c., p. 33; «El texto es límpido. Y con un lenguaje preciso recoge lo mejor de la reflexión latinoamericana sobre el punto; sin caer en las actitudes terroristas de los"que se empeñaban en desconocer el sentido complejo y rico que se expresaba en el término liberación en estos años de creciente compromiso con las luchas de un pueblo explotado y creyente por construir una sociedad humana y justa... A la luz de esta noción de liberación integral debe ser leído el conjunto de los documentos de Puebla». Cfr. G. Gutiérrez, «Pobre y liberación en Puebla», en Rev. Páginas, vol. IV, nn. 21-22 (1979) 21-22.

154. Id. Ib.

155. B.M. HERnÁNDo, Los pasillos de Puebla, Edit. PPC, Madrid 1979, pp. 25-269; T. CABESTRERo, Los teólogos de la liberación en Puebla, Edit. PPC, Madrid 1979, pp. 13-148; Id., Puebla: experiencias y mensajes para todas las Iglesias, PPC, Madrid 1980, pp. 38-47, 69-98; GuSTAvo Gutiérrez, o.c., pp. 1-32; G. Tamayo y otros, El camino hacia Puebla, PPC, Madrid 1979. Hay varias revistas de esta línea que han dedicado números especiales: Rev. Christus, n. 520-521 (1979); Rev. Páginas, vol. IV, n. 21-22_(1979); Rev. Sal Terrae, vol. 67, n. 3 (1979).

156. «El que conozca suficientemente a los teólogos de la liberación, sabe que muchos de ellos no consideran ya una ofensa sino un honor el que se les considere más o menos marxista; más aquí no queremos ni ofenderlos ni honrarlos. Nos atenemos a la expresión «praxis histórica» que tiene una connotación histórica indudable.

...«Praxis histórica» es una expresión marxista fundada en la concepción de la historia como un absoluto. La Verdad y el Bien están contenidos en ella, no en Dios ni en nada que trascienda esa historia. Dicha historia tiene un sentido siempre positivo, pero del cual, son portadores solamente una clase social y un partido... No basta cualquier praxis, tiene que ser «histórica», esto es, progresista, transformadora, «revolucionaria» (no reformista, asistencial de la historia. Fuera de esto no hay verdad y bien. Esa praxis es lo infalible; no es juzgada por nadie y lo juzga todo, también a las pretendidas «verdades» del cristianismo...

Por increíble que parezca, esas conclusiones no dudan en sacarlas, aceptarlas y defenderlas, muchos teólogos de la liberación... Cfr. F. InTERdonATo, Teología Latinoamericana. ¿Teología de la liberación?, Edic. Paulinas, Bogotá 1978, pp. 89-90; B. KLOPPENBURG, Evangelización y promoción humana, Col. Puebla, n. 11, CELAM, Bogotá 1979, p. 39. 
crítico tanto de la teología política como de la teología de la liberación, llama la atención a Gustavo Gutiérrez por no hacer un uso crítico del marxismo en su teología ${ }^{157}$. Fierro reconoce el acierto de la teología de la liberación. Nace después de los existencialismos humanistas para buscar unas teorías críticas y científicas de análisis de la realidad, considerando como mediación adecuada el análisis marxista ${ }^{158}$. El análisis marxista es el inspirador de la reflexión y de los métodos de trabajo y aparece, de alguna forma amalgamado, cristianismo y marxismo. A nivel práctico: «Se busca la alianza estratégica de los cristianos revolucionarios con los marxistas en el proceso de liberación del Continente y se proclama el socialismo inspirado en los principios marxistas como la única alternativa aceptable» ${ }^{159}$.

Clodovis Boff se ha dado cuenta de la deficiencia de ciertos teólogos de la liberación, pues les falta claridad en las reglas de un quehacer teológico científico. Él intenta hacer una reflexión crítica que saque a la luz las condiciones epistemológicas, para que esta teología resulte verdaderamente teología y no simplemente ideologización o discurso persuasivo. Con su estudio, ha intentado dar los instrumentos y mecanismos para hacer una teología científica. Enseña a engarzar, en un conjunto teológico, la mediación socio-analítica del análisis marxista como crítica a la ideologización de la fe, con la hermenéutica bíblica, situada, en función de lo concreto, no intemporal o puramente espiritual, en el sentido de la privatización de la fe, sino acentuando la dimensión pública, política de los eventos salvíficos, sobre todo del Éxodo, así como el carácter subversivo de los profetas y de Jesús frente a las injusticias sociales. Todo esto se dirige hacia el tercer estadio que se refiere a la relación de la teo-

157. A. FIERRO, El evangelio beligerante. Introducción crítica a las teologías políticas. Edit. Verbo Divino, Estella (Navarra) 1975, p. 377; A. LÓpeZ Trujillo, Las teologías de la liberación en América Latina, en Diálogos en el CELAM, bogotá 1974, p. 45.

158. "Gustavo Gutiérrez expresa también la insuficiencia de «una visión aproximativa moralista y 'humanizante' de la realidad, en desmedro de un conocimiento científico, objetivo y estructural de los mecanismos socio-económicos y de la dinámica histórica». La crítica del humanismo deriva así de la adopción de una teoría crítica y científica de la sociedad....

De mayor alcance que la crítica hecha al humanismo es el hecho de que la teología ha dejado de hablar del hombre tanto en su generalísima universalidad cuanto en su individualidad aislada, según es característico del lenguaje humanista, para referirse de manera colectiva a grupos y formaciones sociales históricamente determinadas». Cfr. A. FIERro, O.c., pp. 130-131.

159. B. KloppenBurg, La Iglesia popular en Puebla y su contexto, Col. Puebla, n. 6.2, CELAM, Bogotá 1979, p. 13; Etiam cfr. A. López Trujillo, Teología de la liberación en América Latina, Edic. Paulinas, Bogotá 1975, p. 26; J. CombLIN, «Movimiento e ideologías en América Latina, en Fe cristiana y cambio social en América Latina, Sígueme, Salamanca 1973, pp. 116127; A. PARrA, Fe e interpretaciones de la fe, Bogotá 1976, p. 138; R. Oliveros, Liberación y teología. Génesis y crecimiento de una reflexión (1966-1976), CEP, Lima 1977, pp. 111-476; F. INTERDONATO, Teológía latinoamericana. ¿Teología de la liberación?, Edic. Paulinas, Bogotá 1978, pp. 9-13, 28, 79-80, 89-90. 
logía con la praxis. A partir de la praxis encarnada, liberadora; no simplemente en función de la praxis. Aquí está el criterio de verificación de la teología. Se considera la praxis como el lugar teológico fundamental y se defiende la dialéctica permanente entre teoría (teología) y práctica (política de la fe). En su tesis doctoral, Clodovis, se dedica a poner en claro, los mecanismos de cada una de las mediaciones de los tres estadios, para que resulte una teología con reglas científicas en su teologizar ${ }^{160}$.

Gracias a los teólogos de la liberación conscientes, se ha podido llegar a una conjunción adecuada de las tres etapas:

«... ha conseguido superar ya sea el teologismo (la teología como único discurso válido para pensar lo real-social), ya sea el sociologismo (las ciencias de lo social como úniço discurso legítimo), ya sea el bilingüismo (el paralelismo de dos lenguajes, sin articulación), ya sea la mezcla semántica (la mezcla de dos lenguajes en una articulación mal hecha) ${ }^{161}$.

Aparece, incuestionable, las dos teologías subyacentes en Puebla y las filosofías en las cuales se sustentan. Será fácil deducir las antropologías que tienen por sustrato y que han influido en la elaboración de la antropología de Puebla.

\section{Antropologías filosóficas subyacentes}

Las filosofías que subyacen en las teologías nos orientan para diagnosticar las antropologías que subyacen en Puebla.

Evidentemente, Puebla quiere estar por encima de teologías y filosofías, por ser un documento eclesiástico. Pero, para lograr este intento, ha tenido que superar"las mentalidades que tenían los obispos que elaboraron el documento. $\mathrm{Y}$, parece que, en algunos momentos, han conseguido una cierta síntesis de las dos corrientes principales de las que hemos hecho mención. El mismo Leonardo Boff lo resălta:

La síntesis se operó con la continua acentuación de los dos polos: liberación sí, derechos humanos sí - como quiere una tendencia- pero desde la fe, des-

160. Cl. Boff, Teologia e prática. Teologia do Politico e suas mediasoes, CID, Petrópolis 1978, pp. 21-22.

161. L. Boff, Lectura del documento de Puebla... Bogetá 1980, p. 33; «Lamentablemente Puebla se quedó, en muchos aspectos, en una articulación bilingüista: la teología explícita sobre Cristo, la Iglesia, la evangelización, no se articulan de forma suficiente con el análisis social. Pero en las partes, en las cuales no había preocupación por la ortodoxia, cuando los obispos actuaban como pastores (todas las demás partes del documento), ahí se percibe una bien lograda articulación entre situación-reflexión-acción». Cfr. Id., Ib. 
de el Evangelio, desde la adhesión inequívoca de la totalidad de la doctrina católica - como quiere la otra tendencia- ${ }^{162}$.

Sin embargo, debajo de la síntesis están los dos polos. Ya delimitamos las teologías que predominaban en cada uno de los polos y las filosofías que utilizaban como mediaciones. Por una parte, subyacía en el polo ortodoxo una filosofía nutrida por las corrientes fenomenológica-existencial-personalistatrascendental-dialógica. En el polo innovador está como sustrato filosófico el marxismo. Es muy difícil determinar hasta qué punto influye la filosofía marxista y qué tipo de marxismo, en cada uno de los representantes de esta corriente. Lo que se ve claro es el giro de una sensibilidad existencial y humanista a una conciencia política, a una racionalidad histórica, práctica y dialéctica. La connotación política y pública, la insistencia en la conjunción entre el saber y el obrar. Lo que se puede afirmar es que está bajo el signo de Marx ${ }^{163}$.

Da la sensación de resultar, la antropología de Puebla, una antropología de vía intermedia, un poco al estilo de Mounier. Se recoge lo mejor de la personalización y las adquisiciones de la realización histórica del hombre. Lo primero proviene de la corriente fenomenológica-existencial-personalistatrascendental-dialógica. Lo segundo, trae la huella de la corriente marxista pero purificada. La primera línea sirve más fácilmente de mediación a la antropología cristiana porque está más abierta a lo trascendente, a la relación con Dios. La segunda tiene características que evitan el individualismo, el egoísmo, el idealismo de la primera línea; abre al hombre a lo real, a lo político, a lo concreto, a lo histórico, pero tiene de contrapartida el inmanentismo, la parcialización, el cierre a lo trascendente, la violencia, la lucha de clases, el odio, el ateísmo, el hombre se disuelve en las estructuras.

Las palabras claves utilizadas por Puebla, tienen mucho de la primera línea y purifican las que pueden dar lugar a sospechas de utilización de sistemas de los cuales provienen las segundas. Las que se refieren al ser del hombre, según vimos en la parte inicial de este capítulo, están dentro de la primera corriente. Las que se refieren a la realización histórica, especialmente la liberación, pudiéramos afirmar que de la segunda, pero matizadas, de tal forma, que quedan cristianizadas y sin dar lugar a adherencias a sistemas marxistas, como ya hemos visto.

162. L. Boff, O.c., p. 20; M.A. AsiaIN, 2. «Puebla y la vida religiosa», en Comunidades. Boletín bibliográfico de vida religiosa y espiritualidad; nn. 28-29 (1980) 72-73.

163. «La filosofía de la existencia queda reducida con eso al plàno de las ideologías y sólo el análisis materialista-dialéctico se le reconoce rango de verdadera teoría y auténtico saber. Según Sartre, «el marxismo aparece hoy como la única antropología posible que sea a la vez histórica y estructural, la única, además que toma al hombre en su totalidad, es decir, a partir de la materialidad de su condición». Esto explica la nueva vitalidad que el marxismo ha adquirido...». Cfr. A. FIERro, El evangelio beligerante, Verbo Divino, Estella'(Navarra) 1975, pp. 101-102. 
El ser humano dinámico, el ser integral, el ser más sobre el tener más, el alma encarnada y no simplemente el cuerpo animado, persona humana, realización en la comunidad, opción total y compromiso, dignidad de la persona, libertad, realización en la historia son palabras que se encuentran en las antropologías de Max Scheler, de Gabriel Marcel, de Teilhard de Chardin, de Heidegger, de F. Ebner, de Ricoeur, de Rahner, de E. Coreth ${ }^{164}$.

La realización histórica, en especial la liberación, provienen del movimiento marxista pero purificadas por la concepción cristiana. Detrás de ellas está Marx, Lukács, Bloch, Marcuse, Garaudy ${ }^{165}$.

Según las palabras claves que hemos detectado en la primera parte de este capítulo, como aparecen en la antropología de Puebla, se percibe la preponde-

164. J. MARIAS, El tema del hombre, Espasa-Calpe, Madrid ${ }^{3} 1960$, pp. 242-269; I. LEPP, La filosofía cristiana de la existencia, Edic. Carlos Lohlé, Buenos Aires 1963, pp. 75-94; B. DELFGAAuw, La filosofía del siglo XX, Carlos Lohlé, Buenos Aires, 1965, pp. 118-159; G. MARCEL, «Traslucidez del valor», en Picón y otros, Panorama de las ideas contemporáneas, Edic. Guadarrama, Madrid ${ }^{2}$ 1965, pp. 796-798; A. EtcheverRy, El conflicto actual de los humanismos, Edic. Península, Madrid 1966, pp. 57-128; J. LACroIX, Marxismo, existencialismo, personalismo, Edit. Fontanella, Barcelona ${ }^{4}$ 1969, pp. 85-134; J. RuBio CARRACEDo, Qué es el hombre, Edit. Aguilera ${ }^{2}$ 1973, pp. 83-91; M. HEIDEGGER, El ser y el tiempo, Fondo de Cultura Económica, México ${ }^{2}$ 1962, pp. 11-252; J. Gevaert, Antropología y catequesis, Edic. Don Bosco, CCS, Madrid ${ }^{2}$ 1975, pp. 18-94; A. LÓPEZ QUINTAS, «La antroplogía dialógica de F. Ebner», en Juan de Sahagún LuCAS y otros, Antropologías del siglo XX, Edic. Sígueme, Salamanca 1976, pp. 149. 179; J. de S. LuCAS, Convergencia y personalización en P. Teilhard de Chardin, Id., O.c., pp. 5878; M. MACEIRAS, La realidad personal en el pensamiento de E. Mounier, Id., O.c., pp. 101-124; M. MACEIRAS, La antropología hermenéutica de P. Ricoeur, Id., O.c., pp. 125-148; A. PINTORRAMos, La antropología filośfica de Max Scheler, Id., O.c., pp. 180-201; C. DíAz y M. MACEIRAS, Introducción al personalismo actual, Edit. Gredos, Madrid 1975, pp. 79-100; J.L. RUíz DE LA PEÑA, Espíritu en el mundo. La antropología de K. RHANER, id., O.c., pp. 15-238; H. MANDRINI, La vocación del hombre, Edit. Guadalupe, Buenos Aires ${ }^{5}$ 1976, pp. 111-138; E. CORETH, ¿Qué es el hombre?, Herder, Barcelona 1976, pp. 29-269.

165. CARDONNEL y otros, El hombre cristiano y el hombre marxista, Edit. Estella, Barcelona 1967, pp. 7-154; C. MARX, Manuscritos económico-filosóficos de 1844, Edit. Grijalbo, México 1968, pp. 71-160; Marx y Engels, Manifiesto del Partido Comunista, Edit. Progreso, Moscú, pp. 30-88; R. GARAUdy, Perspectivas del hombre, Edit. Fontanella, Barcelona 1970, pp. 273-452; H. MARCUSE, E. MoRfN, y otros, La nueva imagen del hombre, Rodolfo Alonso Editor, Buenos Aires 1971, pp. 9-159; J.M. GonZÁLEZ-RuíZ, Marxismo y cristianismo frente al hombre nuevo, Fontanella, Madrid 1972, pp. 55-228; A. LÓPEZ TrujILlo, El hombre un ser integral, Edic. Paulinas, Bogotá 1973, pp. 17-32; G. MARKUS, Marxismo y «antropología», Grijalbo, Barcelona 1974, pp. 8-76; G. GuiJARro Díaz, La concepción del hombre en Marx, Edic. Sígueme, Salamanca 1975 , pp. 175-402. Esta obra además de ser un estudio serio y valioso tiene amplia bibliografía sobre el tema; S. LOPEZ, El hombre oprimido, Edic. Paulinas, Bogotá 1975, pp. 11-90; LUMIERET VIE, «Cristiano marxista», Edit. Verbo Divino, Estella (Navarra) 1975, pp. 29-311; P. RICHARD -E. Torres, Cristianismo, lucha de clases y racionalidad socialista, Sígueme, Salamanca 1975, pp. 27-120; J.P. Corral, «Homo absconditus. La antropología de Ernst Bloch», en J. de S. LUCAS, Antropologías del siglo XX, Sígueme, Salamanca 1976, pp. 216-236: J.I. LóPEZ SoRIA, La búsqueda de la posibilidad humana. La antropología de Gy. Lukás, Id., O.c., pp. 202-215; E. VoLANTE, El hombre, Sal Terrae, Santander 1978, pp. 25-332. 
rancia de la llamada corriente ortodoxa donde se remarca lo religioso sin olvidar lo socio-político. La antropología, por tanto, que predomina es la de orientación fenomenológica-existencial-personalista-trascendental-dialógica. Sin embargo, a esta corriente se añaden el rescate de las adquisiciones de valor universal de la segunda vía, sobre todo en la concepción de la realización histórica del hombre. La acentuación en la historia; es transformadora de estructuras si es necesario, además, por supuesto, de la conversión del corazón. La liberación del hombre abarca, no solamente el pecado individual, sino que debe ser liberación total en lo social, en lo político, en lo económico, en todos los niveles en que se desenvuelve el hombre en la historia, pero también en lo trascendente, remarcando lo religioso, lo escatológico. Así, sin descartar la dimensión socio-política del hombre, supera la ideologización marxista y quiere introducir los descubrimientos o desvelaciones de ésta en la visión religiosa bíblica del hombre, con el sustrato de la primera corriente por estar más fácilmente abierta a lo trascendente, a lo religioso.

\section{CONCLUSIONES GENERALES}

1. La «Gaudium et Spes» presenta una antropología personalizante de salvación cristiana.

2. Antropología cristiana del ser y del desarrollo integral en la «Populorum Progressio».

3. Antropología cristiana del progreso integral del ser humano en la «Octogesima Adveniens».

4. Antropología liberadora evangélica en la «Evangelii Nuntiandi».

5. Antropología de salvación liberadora en Medellín.

6. En Puebla hay una antropología de liberación integral o total cristiana. Es una síntesis clarificadora de la antropología anterior de la Iglesia. Síntesis de la orientación personalizante y liberadora bajo la luz cristiana.

7. Puebla trata, en un capítulo especial, de la verdad sobre el hombre aunque no podemos decir que haga una antropología sistemática sino que intenta llamar la atención sobre puntos fundamentales acerca del hombre a la luz de la razón y la fe, para que, a partir de ahí, se juzgue y clarifiquen las diversas ideologizaciones del hombre que pululan en América Latina.

8. Utiliza, Puebla, palabras y conceptos filosóficos para expresar su visión del hombre que aluden a corrientes de pensamiento, pero no se adscribe a sistemas o ideologías. Predomina la mediación de la corriente existencial-personalista-dialógica con cierto matiz histórico-liberador. 
9. Puebla utiliza una espiral hermenéutica al analizar el hombre. Se vale de mediaciones filosóficas pero a la luz de la razón y, especialmente, de la fe. Intenta una visión, una visión integral del hombre a partir de las filosofías y ciencias humanas que conectan con el hombre de hoy pero iluminadas y plenificadas por la luz de la fe.

10. Las mediaciones filosóficas subyacentes pruvienen, en parte, de la corriente ortodoxa de orientación fenomenológico-existencial-personalista y, también, asume las adquisiciones a que ha dado lugar la corriente innovadora con influencia del marxismo, pero Puebla desideologiza, cristianiza y evita el teologismo, el sociologismo, el bilingüismo, la mezcla semántica de los cuales intenta purificarse la Teología de la Liberación.

11. Puebla hace una síntesis de los elementos positivos que le interesa de las dos corrientes, pero sin adherirse a ningún sistema teológico o filosórico. Liberación, derechos humanos como propicia la tendencia innovadora, pero desde la fe, desde el Evangelio, desde la adhesión inequívoca a la totalidad de la doctrina católica como propugna la corriente ortodoxa.

E. ALONSO 